\title{
GenerATING AND TESTING HYPOTHESES ABOUT THE FOSSIL RECORD OF INSECT HERBIVORY WITH A THEORETICAL ECOSPACE
}

\author{
Sandra R. Schachat ${ }^{1, *}$, Jonathan L. Payne ${ }^{1}$, C. Kevin Boyce ${ }^{1}$, Conrad C. Labandeira ${ }^{2,3,4}$ \\ 1. Department of Geological Sciences, Stanford University, Stanford, CA, United States \\ . Department of Paleobiology, National Museum of Natural History, Smithsonian Institution, Washington, \\ DC, United States \\ 3. Department of Entomology, University of Maryland, College Park, College Park, MD, United States \\ 4. College of Life Sciences, Academy for Multidisciplinary Studies, Capital Normal University, Beijing, China \\ * Author for correspondence: sschachat@schmidtsciencefellows.org
}

\begin{abstract}
A typical fossil flora examined for insect herbivory contains a few hundred leaves and a dozen or two insect damage types. Paleontologists employ a wide variety of metrics to assess differences in herbivory among assemblages: damage type diversity, intensity (the proportion of leaves, or of leaf surface area, with insect damage), the evenness of diversity, and comparisons of the evenness and diversity of the flora to the evenness and diversity of damage types. Although the number of metrics calculated is quite large, given the amount of data that is usually available, the study of insect herbivory in the fossil record still lacks a quantitative framework that can be used to distinguish among different causes of increased insect herbivory and to generate null hypotheses of the magnitude of changes in insect herbivory over time. Moreover, estimates of damage type diversity, the most common metric, are generated with inconsistent sampling standardization routines. Here we demonstrate that coverage-based rarefaction yields valid, reliable estimates of damage type diversity that are robust to differences among floral assemblages in the number of leaves examined, average leaf surface area, and the inclusion of plant organs other than leaves such as seeds and axes. We outline the potential of a theoretical ecospace that combines various metrics to distinguish between potential causes of increased herbivory. We close with a discussion of the most appropriate uses of a theoretical ecospace for insect herbivory, with the overlapping damage type diversities of Paleozoic gymnosperms and Cenozoic angiosperms as a brief case study.
\end{abstract}

\section{INTRODUCTION}

In recent years, the number of fossil plant assemblages examined for insect herbivory has increased markedly.

The wealth of available data has already been used to inform a variety of biotic and abiotic phenomena 
(Smith, 2008; Carvalho et al., 2014; Labandeira and Currano, 2013), but raises the question of how to compare the patterns of insect herbivory observed on different host plants or in different assemblages.

An increase in herbivory in deep time can occur in response to various environmental and evolutionary phenomena, demonstrating the need for analytical techniques that can be used to distinguish among them. Two explanations that are commonly invoked as causes of increased insect herbivory are insect and plant evolution, which lead to an expanded suite of feeding behaviors (Labandeira, 2006; Martinez et al., 2019; Wagner et al., 2015), and the nutrient dilution hypothesis, in which a sudden increase in atmospheric $p \mathrm{CO}_{2}$ increases the carbon-to-nitrogen ratio in many plant tissues, increasing the amount of leaf area that each insect must consume in order to ingest a given amount of protein (Bazzaz, 1990). The techniques currently used in paleontological studies do not distinguish among these disparate causes of increased herbivory.

A standardized method for comparing insect herbivory would allow the use of published data to generate null expectations for findings at new localities. In addition, a standardized method would facilitate the differentiation of these and other causes of increased insect herbivory in cases where the distinction is not so clear.

\subsection{The End-Triassic as a hypothetical CASE STUDY}

The end-Triassic extinction event exemplifies the potential utility of statistical methods with the capacity to generate null expectations and disentangle the various potential causes of fluctuations in herbivory. Few latest Triassic floras have been examined for insect herbivory (Ghosh et al., 2015) and, of the geologic periods that contain more than five described insect fossils, the Jurassic is the least studied in this context (McLoughlin et al., 2015; Ding et al., 2015; Pinheiro et al., 2016; Na et al., 2018; Santos et al., 2021).

One could generate any number of predictions about changes in insect herbivory across the end-Triassic event. Patterns of insect herbivory may have remained constant because it is widely agreed that insects did not suffer major losses at the Triassic/Jurassic boundary (Dmitriev and Zherikin, 1988; Labandeira and Sepkoski, 1993; Jarzembowski and Ross, 1996). Insect herbivory may have decreased because plant communities do appear to have endured noticeable turnover and losses across this extinction event (Belcher et al., 2010; Li et al., 2020; Lucas, 2021; McElwain and Punyasena, 2007). The $p \mathrm{CO}_{2}$ spike associated with the end-Triassic event (Knobbe and Schaller, 2017) complicates matters further. Whether or not an increase in $p \mathrm{CO}_{2}$ led to an increase in plant biomass and a corresponding dilution of nutrients such as nitrogen (Mattson, 1980) depends greatly on interacting environmental parameters (Shaw et al., 2002; McMurtrie et al., 2008; Reich et al., 2014). Nutrient dilution has very rarely been directly examined in the plant clades that were present in Triassic and Jurassic ecosystems; this phenomenon has been studied almost exclusively 
in angiosperms, which had not yet evolved at the time of the end-Triassic event (Bazzaz, 1990; Boyce and Zwieniecki, 2012; Ramírez-Barahona et al., 2020).

If data were available, a comparison of insect herbivory levels immediately before and after the endTriassic event would be hampered by the lack of available statistical techniques. The first obstacle would be the lack of a null, or baseline, prediction of the magnitude of change in insect herbivory that would occur from the Late Triassic to Early Jurassic in the absence of a major environmental or evolutionary event. How much variation in insect herbivory is best attributed to statistical noise? How much is best attributed to the passage of time rather than an external trigger? After these sources of variation are taken into account, how much variation remains? The fern- and gymnosperm-dominated Permian, Triassic, and Cretaceous floras that have already been examined for insect herbivory provide an opportunity to generate a null prediction and quantify the uncertainty surrounding it. What is needed is a comparative framework to generate this null prediction.

The second obstacle would be the lack of a comparative framework for disentangling the biotic and abiotic causes of fluctuations in insect herbivory. The environmental perturbation most thoroughly examined in existing studies of insect herbivory, the Paleocene-Eocene Thermal Maximum, or PETM (Wilf and Labandeira, 1999; Currano et al., 2008, 2016), began and ended far too quickly for much plant or insect evolution to have occurred (Zeebe and Lourens, 2019). Many other environmental perturbations, such as the increase in $p \mathrm{CO}_{2}$ at the end-Triassic, which occurred in multiple pulses (Ruhl and Kürschner, 2011), span a long enough interval that abiotic and biotic factors can be confounded.

\subsection{TheORETICAL ECOSPACES IN PALEONTOLOGY}

Morphospaces are a useful tool for quantifying change over time. The axes of empirical morphospaces, constructed with techniques such as principal component analysis, change with the addition of new data; in contrast, the axes of theoretical morphospaces remain unchanged as new data are added (McGhee, 2006). Morphospaces can be multidimensional (Raup, 1967; Lohman et al., 2017), can consist of various twodimensional comparisons (Wilson and Knoll, 2010), or, with sufficiently clear and specific hypotheses, require only two dimensions (Raup, 1967; Gerber, 2017; Balisi and Van Valkenburgh, 2020).

Ecospaces extend the logic of empirical and theoretical morphospaces to ecological data. The canonical use of ecospace in paleontology applies to the marine realm (Valentine, 1969; Bambach, 1983), with an updated version now forming the foundation of many quantitative studies (Bush et al., 2007; Wiedl et al., 2013; Knope et al., 2015; Mondal and Harries, 2016; Frey et al., 2018; Laing et al., 2019). The threedimensional ecospace as updated by Bush et al. (2007) has also been modified for the sedimentary ichnological 
study of terrestrialization (Minter et al., 2017) and for the study of terrestrial vertebrates (Chen et al., 2019).

The primary difference between the two ecospace formulations currently used in studies of marine animals is the number of characters and character states (Novack-Gottshall, 2007; Bush and Novack-Gottshall, 2012). Of note, both theoretical ecospaces for marine animals use qualitative character states (Novack-Gottshall, 2007; Bush et al., 2007).

\section{A THEORETICAL ECOSPACE FOR INSECT HERBIVORY IN THE}

\section{FOSSIL RECORD}

Studies of insect herbivory typically use at least one of three common metrics. The diversity of insect damage types (Labandeira et al., 2007) measures the richness of herbivory. The percentage of leaf area removed by herbivores (known as the herbivory index) and the percentage of leaf specimens with feeding damage both measure the intensity of herbivory; however, the latter is highly sensitive to leaf size, behaves differently from the herbivory index (Smith, 2008), and thus is not recommended as an alternative to the former (Schachat et al., 2018). Although damage type diversity and the herbivory index are often discussed interchangeably, with an increase in either referred to as "more herbivory," they measure fundamentally different aspects of herbivory (Figure 1).

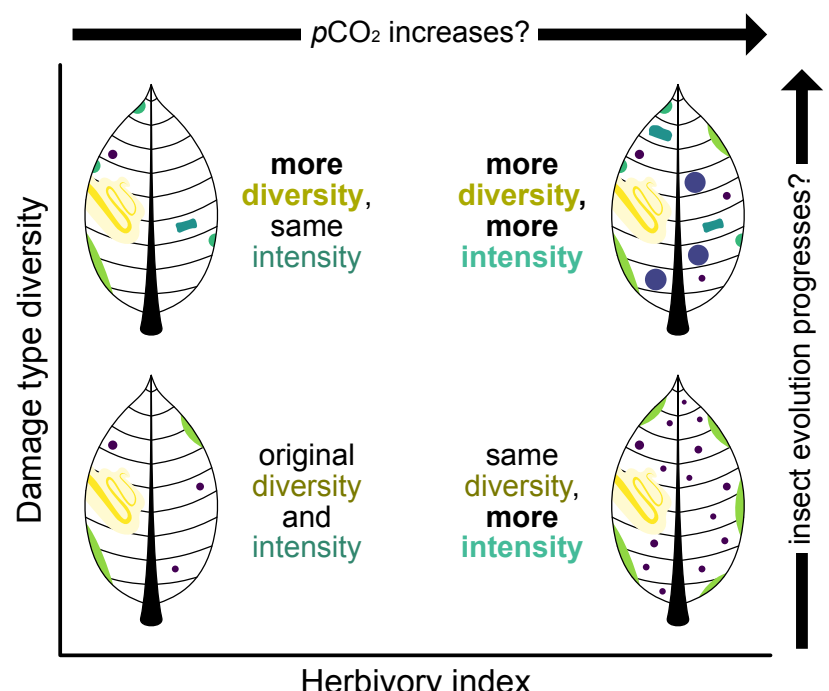

Figure 1: The difference between the diversity and intensity of insect herbivory.

The simplest theoretical ecospace for insect herbivory consists of damage type diversity plotted against the herbivory index. Although this ecospace has not been illustrated or analyzed in previous studies, it holds the potential to disentangle the various causes of increased herbivory. 


\subsection{The Utility of AN ECOSPACE}

The dilution of nitrogen in leaves, caused by increased plant biomass, in turn caused by increased $p \mathrm{CO}_{2}$, will increase the amount of leaf biomass that an herbivore will need to consume in order to ingest enough protein to satisfy its metabolic demands. In other words, an increase in $p \mathrm{CO}_{2}$ is predicted to cause an increase in the intensity of insect herbivory. The increased intensity of herbivory may well permit an increase in the observed diversity of herbivory because the more leaf mass is consumed, the more opportunities there are for the preservation of additional damage types that were present at low frequencies. However, this need not necessarily be the case. When the intensity of herbivory increases, the diversity of herbivory can remain constant or can even decrease.

In contrast, the expanding suite of insect feeding behaviors that developed from the Carboniferous through Permian increased the diversity of herbivory more measurably and consistently than it increased the intensity of herbivory. Whereas arthropod herbivory, probably caused by mites, has been found on Devonian liverworts (Labandeira et al., 2013), the oldest known insect herbivory in the fossil record consists only of external foliage feeding, with no accompanying piercing and sucking or specialized behaviors such as galling and mining (Iannuzzi and Labandeira, 2008). The size of the archetypal herbivorous arthropod and its feeding traces increased, but exhibited no more sophistication or diversity of feeding behavior than already seen with probable mite herbivory on Devonian liverworts. As another example, definitive evidence of leaf mining only appears in the earliest Mesozoic - tens of millions of years after insects began eating plants (Labandeira et al., 1994; Ding et al., 2014) — at a time when the diversity of gall-inducing arthropods also increased (Labandeira, 2021). An increase in the diversity of insect herbivory does not necessitate a corresponding increase in the intensity of herbivory: for example, some Permian gymnosperms have herbivory indices between 3.08\% (Schachat et al., 2014) and 3.95\% (Beck and Labandeira, 1998). These represent the twenty-sixth and thirty-second percentiles, respectively, of angiosperm leaf area removed per year by insect herbivores in extant ecosystems - slightly less than the mean value (Turcotte et al., 2014).

Thus, a bivariate theoretical ecospace can be used to differentiate among the expected impacts of nitrogen dilution versus insect and plant evolution as potential causes of increased insect herbivory. An increase in the diversity of herbivory that outpaces the intensity of herbivory is consistent with insect evolution but not with nitrogen dilution, and vice-versa.

The cyclical Holocene range expansions and contractions of eastern hemlock, Tsuga canadensis L., illustrate why the distinction between the diversity and intensity of herbivory matters (Labandeira, 2012). The decline of hemlock is believed to have been caused by either climate change or outbreaks of insect herbivores (Foster et al., 2006). Increased herbivory on subfossil hemlock leaves would support the 
hypothesis that insects drove eastern hemlock into decline, but only if an increase in the intensity of herbivory exceeds any increase in the diversity of herbivory. The intensity of herbivory would need to increase more strongly than the diversity of herbivory in order for the insect-outbreak hypothesis to be supported because, of the myriad insects known to feed on eastern hemlock (Buck et al., 2005; Dilling et al., 2007), only three - two moths and one conifer aphid - have been identified as possible culprits in the Holocene decline of this species (Filion et al., 2006; Simard et al., 2002; Oswald, 2016; Orwig and Foster, 1998; Labandeira, 2012). Moreover, due to indirect interspecific competition among insect herbivores (Janzen, 1973; Price et al., 1980; van Veen et al., 2006; Kaplan and Denno, 2007), an outbreak of a single herbivore species would quite possibly decrease the total diversity of insect herbivory through suppression of other herbivores. Therefore, range contractions of eastern hemlock caused by insect herbivores would require an increase in the intensity, but not the diversity, of herbivory.

\subsection{EstimATING DAMAGE TYPE DIVERSITY FOR AN ECOSPACE}

Because differences in sampling completeness threaten to bias estimates of damage type diversity (Schachat et al., 2018), the act of comparing damage type diversity to the herbivory index is no simple task. Estimates of the herbivory index are largely robust to differences in sample size: as sampling intensity increases, confidence intervals become narrower but point estimates of the herbivory index do not change perceptibly because a mean is an unbiased estimator (Schachat et al., 2018). For damage type diversity, on the other hand, point estimates and the ranges of confidence intervals vary substantially with sampling intensity because a tally - in this case, a tally of the damage types observed - is a biased estimator that continues to increase as sampling progresses. This is illustrated by the Colwell Creek Pond and Mitchell Creek Flats assemblages from the Early Permian of Texas (Schachat et al., 2014, 2015) which overlap considerably in composition of their floral communities but vary in sampling completeness; the former contains over fifteen times as much broadleaf surface area and over five times as many broadleaf specimens as the latter (Figure S1). As detailed in the supplemental material, we found that the Chao1 estimator is unable to overcome the lack of sampling completeness in insect herbivory datasets. This estimator returns inaccurate and imprecise estimates of damage type diversity whether used alone (Chao, 1987) or in conjunction with rarefaction (Chao et al., 2014).

Coverage-based rarefaction provides an alternative to traditional rarefaction (Chao and Jost, 2012). In traditional, or size-based, rarefaction, curves are scaled by the number of leaves or the amount of leaf area examined. In coverage-based rarefaction, samples are standardized by sampling completeness as indicated by the slope of the rarefaction curve (Good, 1953; Jost, 2010). At the base of a rarefaction curve, sampling 

is incomplete; the slope of the rarefaction curve equals 1 and coverage equals 0 . As sampling approaches completeness, the slope of the rarefaction curve reaches an asymptote-i.e., a slope of 0 -and coverage equals 1 (Figure 2). Thus, with coverage-based rarefaction, damage type datasets are rarefied not to a particular number of leaves but to a particular slope of the rarefaction curve. If a high proportion of damage types are observed on only one specimen, this indicates that coverage is relatively low. In contrast, if a low proportion of damage types are observed on only one specimen, coverage is relatively high. Coverage-based rarefaction is performed by removing the rarest damage types from the dataset until coverage is reduced to a predetermined threshold such as 0.8 (Figure 3).

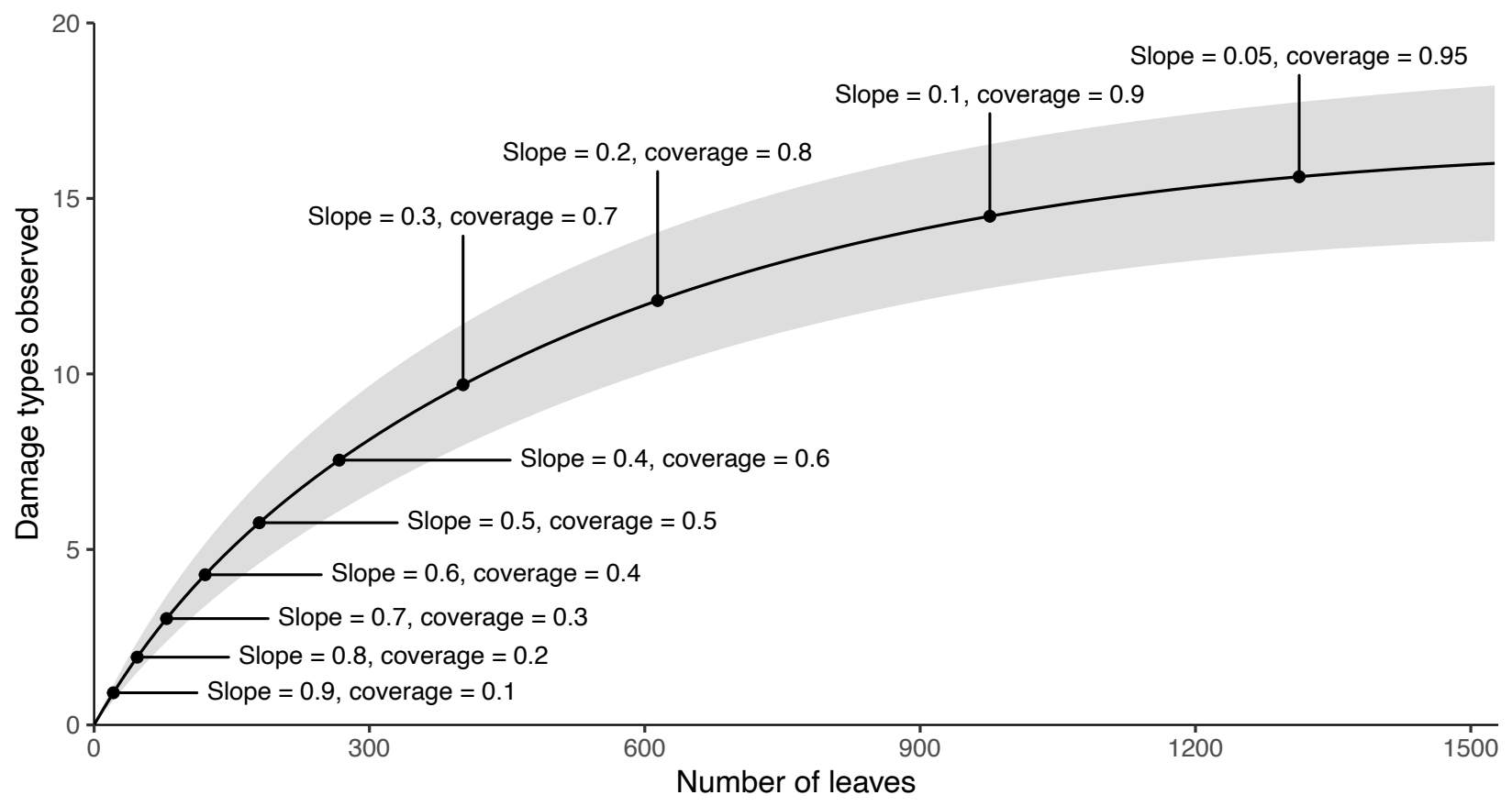

Figure 2: An illustration of the relationship between size-based and coverage-based rarefaction, showing that sample coverage is determined by subtracting the slope of the rarefaction curve from 1 . These data are from the Hlatimbe Valley 213 assemblage (Labandeira et al., 2018), which was selected for inclusion here because it is also featured in Figure 3. 
(A) Nuwejaarspruit 111B, sample coverage $=0.82$

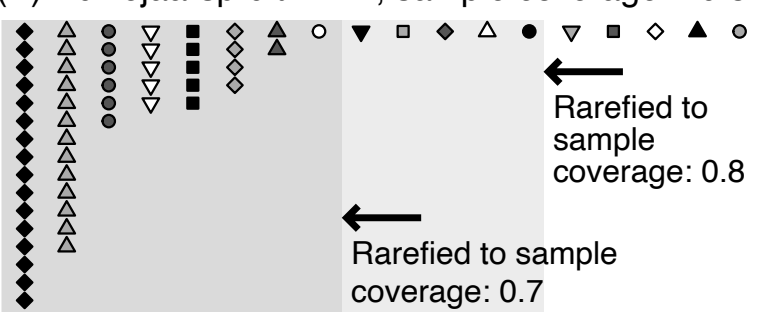

(B) Sani Pass 111, sample coverage $=0.85$

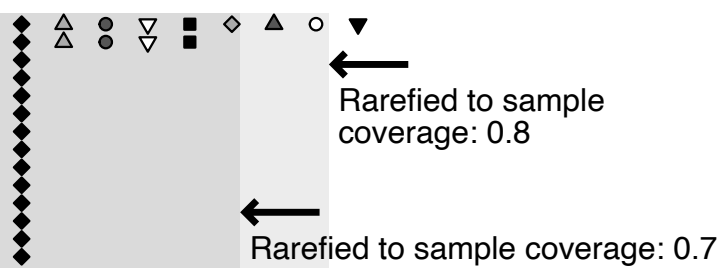

(C) Klein Hoek 111B, sample coverage $=0.90$

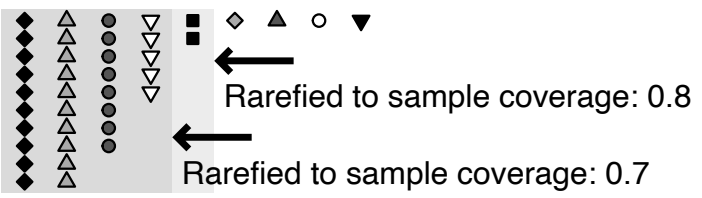

(D) Greenvale 121, sample coverage $=0.95$

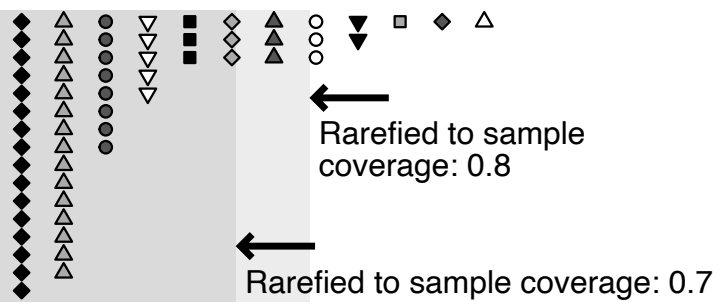

(E) Hlatimbe Valley 213, sample coverage $=0.97$

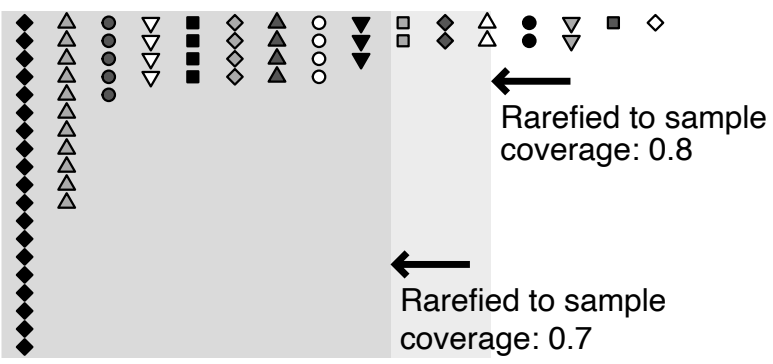

Figure 3: An illustration of the concepts of sample coverage and of rarefaction by sample coverage. The five assemblages illustrated here were examined by Labandeira et al. (2018). For each assemblage, the sample coverage for the complete dataset is listed in the title. The lightest gray boxes denote the damage type diversity at each assemblage when rarefied to a sample coverage of 0.8 , and the darker gray boxes denote damage type diversity rarefied to a sample coverage of 0.7 . The assemblages are organized from the lowest to highest levels of sample coverage. Each column of symbols represents a damage type, and the number of times each symbol is illustrated represents the number of specimens on which the damage type was observed. (A) has relatively low sample coverage because the majority of damage types are observed on only one specimen. In contrast, (E) has relatively high sample coverage because so few damage types are observed on only one specimen. 


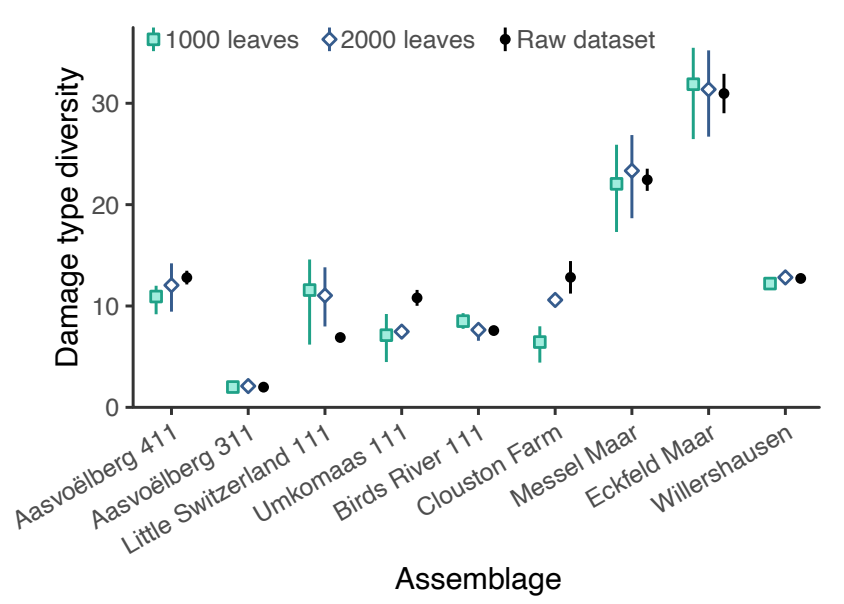

Assemblage

Because coverage-based rarefaction follows the replication principle (Chao and Jost, 2012) it provides an unbiased and consistent estimator of damage type diversity that is robust to sample size, leaf size, and fragmentation. In statistical parlance, an "unbiased estimator" is an estimator whose average expected value for a sample is equal to the true value in the population from which the sample was drawn. In other words, whether the dataset for a given fossil assemblage reaches a sample coverage of 0.85 or 0.99 , the estimated damage type diversity will, on average, be the same when the dataset is rarefied down to a sample coverage of 0.8. A "consistent estimator" converges on the true population value as sample size becomes large. In other words, if one fossil assemblage reaches a sample coverage of 0.85 and another reaches a sample coverage of 0.99, the uncertainty surrounding damage type diversity rarefied to a sample coverage of 0.8 will be smaller for the latter, more completely-sampled assemblage. The assemblages listed in Tables 1 and 2 with over 7,000 leaves examined were randomly subsampled down to 1,000 and 2,000 leaves in a procedure that was iterated 1,000 times (Figure 4). Whereas accuracy and precision typically suffer when these assemblages are subsampled down to 1,000 or even 2,000 leaves before performing traditional, size-based rarefaction (Figure S3), the loss of precision and accuracy are minimal with coverage-based rarefaction (Figure 4). The loss of precision with coverage-based rarefaction is far less severe than with size-based rarefaction (Figure S3) or with the Chao1 estimator (Figure S2) and still allows the differentiation of damage type diversity among many assemblages. With coverage-based rarefaction, the most notable lack of overlap among the confidence intervals for the different sample sizes occurs for Clouston Farm (Figure 4). The confidence intervals overlap to a reassuring extent for half of the pre-angiosperm and all of the angiosperm assemblages (Figure 4).

Figure 4: Precision and accuracy of estimates of damage type diversity generated with coverage-based rarefaction.

An additional benefit of coverage-based rarefaction is that, because samples are standardized by damage type completeness rather than number of leaves examined, this method is relatively robust to the 
variable inclusion of non-broadleaf specimens, from pine needles to axes to seeds, in the datasets for different assemblages. Some published comparisons of insect herbivory among assemblages include broadleaf specimens only, whereas others include all plant specimens. Some floral assemblages do not contain any seeds and other non-foliar specimens, and of those that do, the non-foliar specimens may or may not be included in published datasets. Within angiosperm-dominated floras, ferns, gymnosperms, and monocots may (Robledo et al., 2018; Giraldo et al., 2021) or may not (Azevedo Schmidt et al., 2019; Currano et al., 2019) be examined. Criteria for inclusion in comparative analyses can even vary within the same research group, with some workers using a wider definition of foliage that includes needles, liverworts, phyllids, photosynthetic wings of seeds, and even flattened horsetail axes (Prevec et al., 2009; Labandeira et al., 2018), and others using a narrower definition restricted to multi-veined broad leaves or leaves with a defined midvein (Schachat et al., 2014, 2015, 2018, 2020). (For additional information, see "criteria for inclusion of leaves and damage types" in the supplemental information.)

Because non-broadleaf specimens typically contain little or no evidence of insect herbivory, they contribute little or nothing to metrics of damage type sampling completeness and will therefore have minimal or no impact on estimates of damage type diversity at an assemblage. And, because some herbivory datasets code plants as morphotypes only, with no information on whether the morphotype represents a dicot or a conifer (Maccracken, 2020), these datasets cannot be analyzed with traditional size-based rarefaction. However, these datasets can indeed be analyzed with coverage-based rarefaction. Plant organs that contain little or no insect damage, such as axes and pine needles, contribute little or nothing to estimates of sample coverage, and thus their inclusion in coverage-based damage diversity estimates does not bias the estimates downward.

A remaining question is the confidence level that should be used in confidence intervals for rarefied damage type diversity. Schachat et al. (2018) used $84 \%$ confidence intervals, rather than $95 \%$, because the comparison of two curves with $84 \%$ confidence intervals yields a Type I error rate below $5 \%$. However, the confidence intervals generated with the iNEXT package rely in part on extrapolated diversity, which is shown above to be biased by sample size in the case of damage type diversity datasets. As a result, the confidence intervals generated by iNEXT are narrower than those generated with the iterative procedure of Schachat et al. (2018). Therefore, we recommend generating $95 \%$ confidence intervals with the iNEXT package for use in the ecospace.

\subsubsection{CONSIDERATIONS FOR ASSEMBLAGES WITH INSUFFICIENT COVERAGE}

Just as size-based rarefied estimates of damage type diversity are conducted at a predetermined level of sampling, such as 400 leaves, coverage-based rarefied estimates of damage type diversity require a predetermined level of coverage, or sampling completeness. Here we rarefy to sample coverage 0.8 . 
Coverage increases throughout the sampling process as a function of sample size, the evenness of damage types, the richness of damage types, and the frequency with which damage types occur. Accordingly, there is no predetermined number of leaves or amount of surface area at which an assemblage is assured to have sufficient coverage.

The impossibility of assessing all assemblages that have been sampled to a certain size, such as 400 leaves or $1000 \mathrm{~cm}^{2}$ of surface area, is perhaps the only disadvantage of using coverage-based rarefaction instead of size-based rarefaction. Five of the assemblages in Tables 1 and 2 have insufficient coverage for rarefaction to sampling completeness of 0.8: the Permian Wuda (Feng et al., 2020) and Bletterbach (Bernardi et al., 2017) assemblages, and the Triassic Qachasnek 111, Kraai River 111, and Konings Kroon 222 assemblages (Labandeira et al., 2018). (The Triassic Makoaneng 111 and Konings Kroon 111A assemblages both have a total sample coverage of 0.79 . We extrapolated the damage type diversity at a sample coverage of 0.8 for these two asseblages, but do not recommend extrapolating diversity estimates for assemblages with coverage below 0.79 , as discussed in the supplemental material.) All of these contain little damage. Of note, the Boesmanshkoek 112 assemblage from the same Triassic study contains only two damage types, but these occur frequently enough that the assemblage has sufficient coverage. Thirty-nine of the 44 assemblages with fewer than 1,000 leaves listed in Table 3 have sufficient coverage as well. Of the ten assemblages with coverage below 0.79 , eight have values between 0.45 and 0.69 , and the remaining two assemblages have values of 0.70 and 0.72 . Rarefying to a sample coverage of 0.7 would decrease the power to detect differences among assemblages while providing a negligible increase in the number of assemblages included.

The best way to handle assemblages with insufficient coverage depends on the number of leaves examined and the temporal scope of the study. In the case of assemblages with only a few hundred leaves, estimates of damage type diversity comparable to those generated with coverage-based simply cannot be calculated. For studies such as that of Labandeira et al. (2002b) with a limited temporal scope and a large quantity of assemblages, many of which contain small numbers of leaves, the exclusion of assemblages that do not reach sufficient sample coverage can decrease the power of the study to detect changes in herbivory through time by excluding assemblages whose low sample coverage may be due to insufficient sampling or a true scarcity of damage types. In cases such as this, size-based rarefaction curves scaled by the amount of surface area sampled rather than the number of leaves sampled (Schachat et al., 2018) are the most appropriate choice. These size-based estimates of damage type diversity cannot be incorporated into meta-analyses that use coverage-based rarefaction. We conducted simulations to evaluate extrapolated estimates of damage type diversity in cases when the raw dataset does not reach a sample coverage of 0.8 , and found that extrapolated estimates are not reliable and are often invalid (Figure S4). 


\subsection{Evaluating other Potential Dimensions of AN ECOSPACE FOR HERBIVORY}

Whereas the intensity and diversity of insect damage are the two most commonly studied aspects of insect herbivory and are the two most obvious choices for dimensions of an ecospace, additional dimensions bear consideration. Examples discussed here include the proportion of feeding occurrences belonging to external foliage feeding and to piercing and sucking; damage type evenness; damage type evenness compared to floral evenness; floral diversity; damage type diversity compared to floral diversity; and the prevalence of each functional feeding group, best quantified through the amount of herbivorized surface area. Feeding occurrences are defined here as the number of times that a damage type occurs on an individual plant specimen; these data are rarely collected in studies of fossil herbivory (Robledo et al., 2018; Ma et al., 2020).

The first additional dimension is the prevalence of external foliage feeding, a functional feeding group containing generalist modes of herbivory in which an insect typically chews on a leaf. The proportion of feeding occurrences belonging to external foliage feeding - as opposed to piercing and sucking or specialized herbivory such as mining and galling - is perhaps the metric with the greatest potential to distinguish between insect evolution and nutrient dilution, the two most common explanations of increased herbivory invoked by paleontologists.

When nutrient dilution occurs, the prevalence of piercing-and-sucking feeding damage - whether measured as number of damage types, percentage of leaf area damaged, or number of feeding occurrences - will likely remain constant. This is because piercing-and-sucking insects often feed by puncturing individual phloem cells (Will et al., 2013). Whereas the number of phloem cells may increase in response to nutrient dilution, the content of each cell and the pressure within each cell will most likely remain the same. Therefore, piercing-and-sucking insects that feed on phloem will not need to feed more in order to meet their nutritional requirements. Similarly, when nutrient dilution occurs, the number of specialized mining and galling damage types is unlikely to increase, as is the number of occurrences of these damage types. Gall-inducing insects hijack their host plant's metabolism; their control over the tissues that form galls may well be sufficient to shield them from the effects of nutrient dilution. However, the amount of surface area lost to mining may increase if larvae need to make longer mines in order to fulfill their nutritional requirements. External foliage feeding is the only broad category of herbivory for which one would expect to see the number of feeding event occurrences increase with nutrient dilution. External foliage feeders, like leaf miners, will need to consume more leaf surface area if nutrient dilution reduces the nutritional quality of the leaf blade. And unlike leaf miners, external foliage feeders have the opportunity to partition the additional leaf surface area they consume among multiple feeding event occurrences. 
Whereas "damage type diversity" as discussed here is a measure of the richness of damage types, the evenness of herbivore damage also holds potential to inform differences in herbivory among assemblages. Gunkel and Wappler (2015) extended the insights of Olszewski (2004) regarding the relationship between rarefaction and evenness to the study of insect herbivory. A number of other authors have also quantified evenness - of the floral community, of damage types, or both - when evaluating insect herbivory in the fossil record (Wappler et al., 2015; Currano et al., 2019; Azevedo Schmidt et al., 2019). These too can be used as additional dimensions of the herbivory ecospace. Of note, the frequencies of each plant host and damage type can be replaced with their respective surface areas when calculating evenness metrics.

Another metric, related to evenness, is the offset between the prevalence of each plant host and the prevalence of insect damage on it. For example, if a locality contains two plant hosts, one that accounts for $70 \%$ of total leaf surface area and another that accounts for $30 \%$, a null expectation would be that $70 \%$ of herbivorized surface area would belong to the first plant host and 30\% would belong to the second. The extent to which this null expectation is violated can be quantified by summing the absolute values of the differences between each plant host's prevalence in the assemblage and the proportion of herbivorized leaf area that it contains. In this example, if the first host plant contains $65 \%$ of herbivorized leaf area and the second contains $35 \%$, the offset between total and herbivorized leaf area summed across the locality is $|0.7-0.65|+|0.3-0.35|=0.1$. If, on the other hand, the first host plant contains only $25 \%$ of herbivorized leaf area and the second contains $75 \%$, the offset between total and herbivorized leaf area summed across the locality is $|0.7-0.25|+|0.3-0.75|=0.9$. This evenness-offset score ranges from 0 (no offset) to 2 (maximum offset). This metric can be leveraged as an additional dimension for an herbivory ecospace. An $84 \%$ confidence interval for this evenness-offset score can be generated by resampling plants and damage type occurrences, with replacement, to the amount of surface area observed in the original dataset, calculating an evenness-offset score for the resampled datasets, and iterating this process 5,000 times. (For discussion of the number of iterations needed, see the supplemental material.)

Floral diversity, and the relationship of floral diversity to damage type diversity, can comprise additional dimensions of the herbivory ecospace. A damage-diversity-to-floral-diversity ratio, in which rarefied damage type diversity is divided by rarefied floral diversity, holds the potential to reveal the extent to which floral diversity underlies damage type diversity. A confidence interval for this ratio can be calculated by randomly selecting a value within the confidence interval for rarefied damage type diversity, randomly selecting a value within the confidence interval for rarefied floral diversity, dividing the former by the latter, and iterating this process 1,000 times. The number of specimens required to rarefy floral diversity to sample coverage of 0.8 may differ from the number of specimens required to rarefy damage type diversity to sample coverage of 0.8 .

Lastly, the prevalences of each functional feeding group within an assemblage can comprise yet more 
dimensions of the ecospace. Ideally, the prevalence of each functional feeding group would be quantified by the absolute and relative amounts of herbivorized surface area that it represents. However, as noted above, surface area measurements are unavailable for nearly all herbivory datasets. Thus, the proportion of damage type occurrences attributable to each functional feeding group can instead be used as a proxy. Confidence intervals for the proportions of either herbivorized area or damage type occurrences can be calculated by iteratively resampling with replacement as discussed above.

Additional measures, such as bipartite network metrics (sensu Blüthgen et al., 2008) and host specificity, require so much data that it may not be possible to precisely and accurately estimate them with a typical fossil herbivory dataset. This is further discussed in the supplemental material (Figure S6; "evaluation of other metrics").

\subsection{THE OPTIMAL NUMBER OF DIMENSIONS IN THE ECOSPACE}

When traditional multivariate statistics are used in ecological studies, scree plots allow researchers to determine the number of axes that warrant interpretation (McGarigal et al., 2013). We are not aware of any analysis comparable to a scree plot that would facilitate determination of whether all of the above dimensions of an ecospace warrant consideration. However, we also do not see any a priori reason to expect that all of these dimensions will be informative in all studies of insect herbivory. We have listed all of these dimensions because they are already used in studies of insect herbivory and we aim to standardize statistical practices and to encourage use of the most robust metrics. It is entirely reasonable to assume at the beginning of any study that damage type diversity and the herbivory index are the only necessary dimensions of this ecospace unless another dimension can directly address any hypotheses under consideration. If two or more dimensions of an ecospace are highly colinear, or if one or more dimensions contribute only statistical noise, the most appropriate course of action is to eschew those dimensions.

\section{The AMOUNT OF SAMPLING REQUIRED}

The ability to determine a priori how much sampling is needed for a given assemblage - or whether an assemblage contains sufficient material for robust comparisons with other assemblages - would allow investigators to allocate their efforts most efficiently. Unfortunately, our results show that neither the number of leaves nor the amount of surface area in an assemblage are reliable predictors of sufficient sampling for coverage-based rarefaction. The frequency of damage on leaves is a far more reliable predictor, but is much more difficult to estimate prior to data collection.

One advantage of coverage-based rarefaction is that it can be integrated with a "stopping rule". In the case 
of the sample coverage threshold of 0.8 used here, sample coverage can be re-calculated whenever new data are added to a dataset and sampling can be considered sufficient when the threshold of 0.8 has been reached. Although stoppage of data collection at this threshold would allow a maximum number of assemblages to be examined and compared, it is worth noting that the confidence intervals surrounding damage type diversity and the herbivory index will narrow if sampling continues beyond a sample coverage of 0.8 .

As discussed in a recent contribution, estimates of damage type diversity require more sampling than estimates of the herbivory index do (Schachat et al., 2020). As shown in the supplemental material ("evaluation of other metrics"; Figure S6), even more sampling would be needed to estimate host-specificity of individual damage types and to estimate more complex metrics that match particular damage types with particular host plants; the extreme sensitivity of such metrics to sample size has already been established in the neontological literature (Blüthgen, 2010).

In fact, it has yet to be demonstrated that any realistic amount of sampling completeness in studies of fossil insect herbivory is adequate for reliable calculation of complex metrics such as bipartite network properties. The sampling completeness necessary for reliably calculating bipartite network properties could be established by iteratively subsampling an assemblage to half of its original leaf surface area and calculating network properties for each subsample. The results of this subsampling routine could be used to generate a confidence interval for each network property. If, for each network property, the confidence interval is narrow enough that it does not overlap with the confidence intervals generated for other assemblages subsampled to the same amount of surface area, the amount of surface area available is sufficient to reliably calculate network properties. Of note, however, the requisite amount of surface area will vary with the dominancediversity structure of the plant host and damage type communities at each assemblage. It is not yet clear whether it is worth pursuing sufficient sampling for the implementation of bipartite network analyses.

\section{Generation of NULL Hypotheses}

The study of insect herbivory in the fossil record has become vastly more popular over the past few decades. Early studies that examined patterns of insect herbivory caused by a major event, such as a mass extinction, had only one available option: to quantify the magnitude of the differences in insect herbivory before and after the event in question. A question that could not be addressed at the time those early studies were conducted, but can be addressed now, is whether the amount of change in insect herbivory after a major event exceeds the amount of change that one would expect if the event had not happened.

Returning to the end-Triassic example mentioned in the Introduction, a number of factors preclude the attribution of changes in herbivory across a boundary to the events that occurred at the boundary. First, the 
difficulty of finding floral assemblages deposited immediately before or after the Triassic/Jurassic boundary, and establishing their proximity to the boundary, necessitates that this event be examined with Triassic and Jurassic floras that are separated by millions of years - a long enough time for plant and insect communities to change without any extraordinary abiotic events. Second, even within a single basin, plant communities, soils, precipitation, temperature, and perhaps also predators and parasitoids change with major abiotic events, introducing various potential causes of changes in insect herbivory that may not be directly related to the abiotic event in question (Currano et al., 2019). On a related note, although nutrient dilution is expected to cause an increase in the herbivory index, several of these alternative phenomena could also cause such an increase. Third, extant ecosystems demonstrate that coeval plant communities in close geographic proximity can vary tremendously due to microclimate and other factors such as soil type and frequency of disturbance (Tamme et al., 2010); the difficulty of identifying a characteristic flora for a particular place and time makes it more difficult still to compare characteristic patterns of insect herbivory for a particular place across different time slices.

To overcome these obstacles, many studies of insect herbivory have examined multiple plant assemblages from each time interval of interest (Labandeira et al., 2002a; Currano et al., 2008; Wappler, 2010; Donovan et al., 2018). If the assemblages from each time interval form distinct clusters, in an NMDS plot for example, this provides far stronger evidence of change over time than can be gleaned from only two assemblages. The outstanding question is how much change over time is to be expected in the absence of an event such as an environmental disturbance (the amount of change expected as a null hypothesis), and how much change can be attributed to the event under consideration (the amount of change needed to support the alternative hypothesis that the event in question caused significantly more change in patterns of insect herbivory than can be explained only by the passage of time).

The theoretical ecospace outlined here holds the potential to go beyond an examination of the number of damage types observed per number of leaves, by quantifying the following. First is the amount of variation in insect herbivory to be expected among coeval floras that occur in close proximity and have slightly different plants, soils, depositional conditions, and microclimates. Second is the amount of variation in insect herbivory to be expected on the time scales examined in relevant studies $(10 \mathrm{Kyr}, 100 \mathrm{Kyr}, 1 \mathrm{Myr}$, $10 \mathrm{Myr}$ ) in the absence of any major environmental changes. Third is the amount of, and the nature of, changes in insect herbivory associated with environmental changes, such as the Cretaceous/Paleogene Event (Labandeira et al., 2002b; Donovan et al., 2018) and the Paleocene/Eocene Thermal Maximum (Currano et al., 2008). Fourth is the amount of, and the nature of, changes in insect herbivory associated with insect evolution over tens of millions of years. Nearly any comparison of floral assemblages will yield evidence of different patterns of insect herbivory; the key question is how much change needs to occur in order to 
rise above background levels. In the future, as data become available to include increasing numbers of assemblages in this theoretical ecospace, confidence intervals can be established in each dimension for these four types of changes in insect herbivory.

Traditional morphospaces have already been leveraged to generate null hypotheses and to disentangle the results of directional evolution from changes through time that are best attributed to a "random walk" model (Pie and Weitz, 2005; Puttick et al., 2020). The same logic can be extended to the study of insect herbivory in the fossil record.

\section{Preliminary RESUlts}

\subsection{Comparable herbivory during the Paleozoic, Mesozoic, and Cenozoic}

When damage type diversity from the assemblages in Tables 1,2 , and 3 is plotted against time, the most striking result is the overlap of damage type diversity among Permian, Triassic, and angiosperm-dominated assemblages (Figure 5). The dataset analyzed here contains five times as many angiosperm-dominated assemblages as it does Paleozoic assemblages, and over three times as many angiosperm-dominated assemblages as Triassic assemblages. And yet the Laguna Polina assemblage from the Permian of Patagonia (Cariglino, 2018), the Kühwiesenkopf assemblage from the Triassic of Italy (Labandeira et al., 2016), and Cyphergat 111A assemblage from the Triassic of South Africa (Labandeira et al., 2018) all contain damage type diversities within the highest $12 \%$ of values for angiosperm-dominated assemblages. The supplemental material includes a sensitivity analysis and a discussion of the role of rare damage types in diversity estimates. 


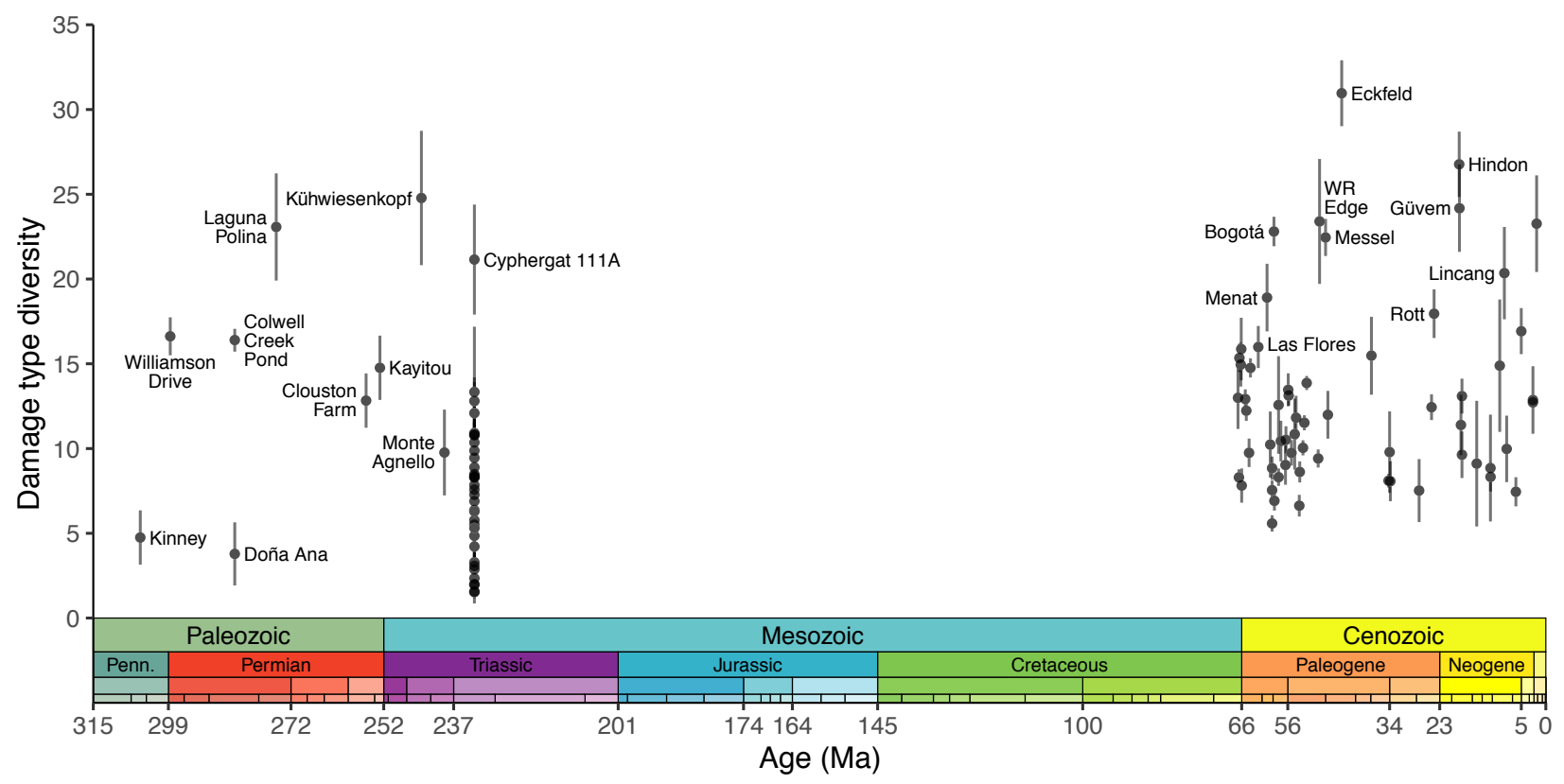

Figure 5: Damage type diversity estimated with coverage-based rarefaction, plotted against time.

The minimal increase in the upper bound of damage type diversity from the Paleozoic through Cenozoic is further supported by the two-dimensional ecospace which we advocate for here (Figure 6). The available data are sufficient to include only eight assemblages in this ecospace: Williamson Drive (Xu et al., 2018) and Colwell Creek Pond (Schachat et al., 2015) from the late Paleozoic; and Daiye Spa, Hubble Bubble, PN, Fifteenmile Creek, Republic, and Bonanza from the interval surrounding the Paleocene/Eocene Thermal Maximum (Wilf et al., 2001; Labandeira, 2002; Currano et al., 2008, 2010, 2016). This ecospace also supports the prediction outlined earlier in this contribution that an abiotic event-in this case, exemplified by the Hubble Bubble locality during the PETM — can indeed lead to a change in damage type diversity, but most clearly manifests with a change in the herbivory index.

This finding of similar damage type diversities in Paleozoic, Triassic, and angiosperm-dominated assemblages may be somewhat surprising given the angiosperm potential for uniquely high productivity (Boyce and Zwieniecki, 2012) and their tremendous diversity (Soltis and Soltis, 2004) - and especially their codiversification with insects (Pellmyr, 1992). Leaf mining, for example, is a highly specialized form of herbivory that accounts for a wide array of described damage types (Eiseman, 2019) and occurs overwhelmingly on angiosperm leaves (Scott et al., 1992). One might expect the origin of angiosperms to have caused a diversification of leaf-mining insects, which in turn would have caused an increase in damage type diversity. However, the data do not support an overall increase in damage type diversity in angiosperm-dominated assemblages.

The difficulty of quantifying the role of angiosperm diversity and biomass in shaping extant ecosystems 


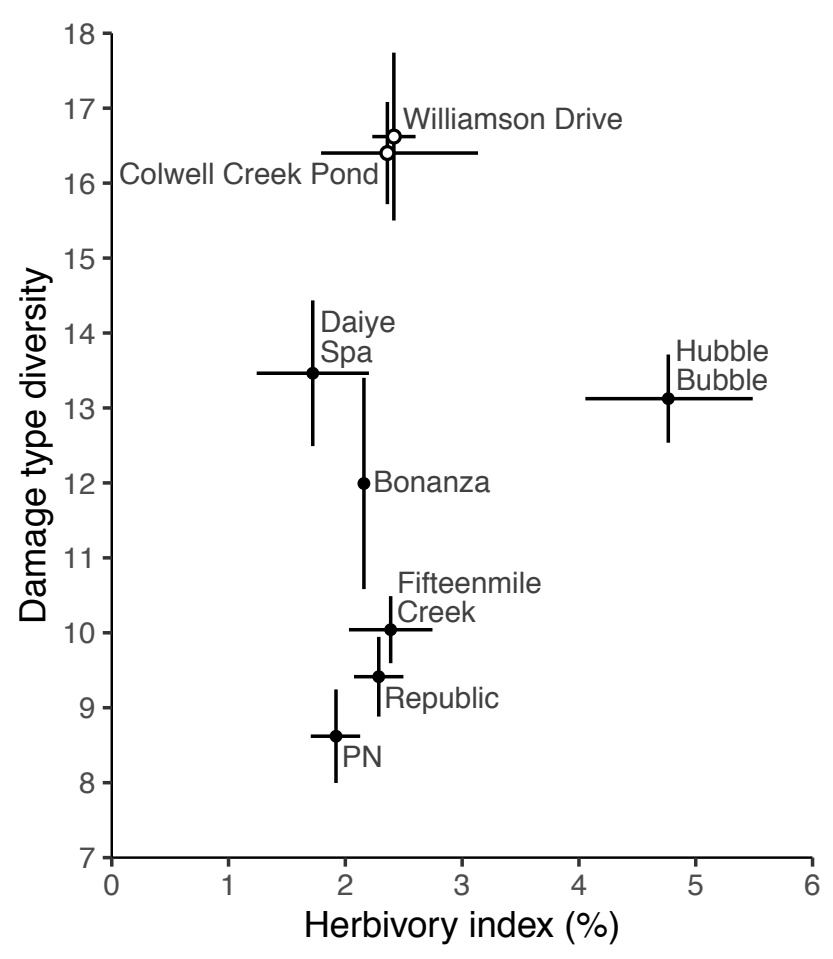

Figure 6: Damage type diversity plotted against the herbivory index in a two-dimensional ecospace. Paleozoic localities are denoted with white circles and angiosperm localities are denoted with dark circles. The confidence intervals for the herbivory index were derived with the method of Schachat et al. (2018) for Williamson Drive and Colwell Creek Pond, and with the method of Currano et al. (2016) for all other assemblages.

stems largely from their overwhelming dominance. If angiosperms accounted for $70 \%$ of the diversity and biomass of land plants, any disproportionate ecological role they may fulfill—for example, if they hosted $95 \%$ of leaf mine damage types - would be easier to establish. But, because angiosperms account for approximately $96 \%$ of described vascular plant species (Christenhusz and Byng, 2016), any disproportionate ecological role they may fulfill-for example, if they hosted $98 \%$ of leaf mine damage types - may be statistically indistinguishable from the null expectation of this ecological role (in the case of this example, that angiosperms would host $96 \%$ of leaf mine damage types). To use another hypothetical example, if it were known with absolute certainty that angiosperms host only $93 \%$ of leaf mine damage types, one could still say that the overwhelming majority of leaf mine damage types occur on angiosperms, such that leaf mine diversity and thus overall damage type diversity likely increased alongside the radiation of flowering plants. 


\subsection{THE ROLE OF $p \mathrm{CO}_{2}$ DEPENDS ON THE RATE OF ATMOSPHERIC CHANGE}

The changes in damage type diversity in Figure 5 show no general relationship with $p \mathrm{CO}_{2}$. For example, the Kayitou assemblage dates to the late Lopingian, an interval for which many geochemical models reconstruct high $p \mathrm{CO}_{2}$ (Mills et al., 2019), but Kayitou does not have particularly prevalent insect damage (Liu et al., 2020) nor is its damage type diversity unusually high (Figure 5).

Rising $p \mathrm{CO}_{2}$ may drive nutrient dilution and, thus, increased insect herbivory, but stable $p \mathrm{CO}_{2}$ - whether high or low-may favor instead compensatory physiological changes that allow for stable rates of carbon fixation under different atmospheres. The carbon cycle perturbation of the PETM may have constituted an atmospheric change too rapid for plants to adapt to; it is under this circumstance that nutrient dilution may be most likely to occur. For this reason, the increased intensity of herbivory seen at the PETM is not a template for the changes in herbivory that would occur if $p \mathrm{CO}_{2}$ rose slowly enough for plants to remain well adapted to the atmospheric composition.

\section{CONSIDERATIONS FOR FUTURE STUDIES}

Overlapping damage type diversities through time are far easier to demonstrate than changing diversities. Labandeira et al. (2002b) evaluated damage type diversity before and after the end-Cretaceous event. Their study included 17 beds with 200 or more dicot leaves: eleven Cretaceous and six Paleogene. Coveragebased rarefaction supports the authors' conclusion that damage type diversity was higher during the latest Cretaceous than during the earliest Paleogene. However, damage type diversities vary widely within each of these two intervals. These fossil beds all occur within the same basin, and the beds from each interval are dominated by a single type of depositional environment. Aside from the first-order finding of less herbivory in Paleogene beds, variation in damage type diversity does not occur in a predictable manner through time.

This variability observed within 1 Myr in a single basin highlights the difficulty of establishing a representative amount of damage type diversity for a particular interval - even for a single depositional environment within a single basin during a very small amount of geologic time. The low signal-to-noise ratio among the damage type diversities for a pooled set of assemblages highlights the difficulty of identifying temporal trends in insect herbivory.

Additional factors further conceal temporal trends. First is the obvious variability among assemblages in geographic location, insect taxa, plant taxa, soil type, and climate. Second is uneven sampling across time. No studies of herbivory for an entire flora have been published for the Jurassic, and within the Cenozoic, the Paleogene is far better sampled than the Neogene or Quaternary. Third, especially for the 
Cenozoic, assemblages are chosen for study based largely on their relevance to events such as the endCretaceous extinction (Labandeira et al., 2002b; Wilf et al., 2006; Wappler et al., 2009; Donovan et al., 2017, 2018), the Paleocene/Eocene Thermal Maximum (Wilf and Labandeira, 1999; Wilf et al., 2001; Currano et al., 2008; Currano, 2009; Currano et al., 2010), and the Early Eocene Climatic Optimum (Currano et al., 2016, 2019). The assemblages for which we have data are disproportionately likely to come from the least representative part of a geologic interval, such as the very earliest Eocene, because these time slices epitomize the phenomena that underlie paleontologically interesting ecological and evolutionary questions. The uneven temporal distribution of studied assemblages adds far more variability to reconstructed long-term trends than one would expect if assemblages were chosen for study in an unbiased manner, and has the potential to obscure these trends.

\section{CONCLUSIONS}

As the proliferation of free software packages and online databases continues, it becomes easier to run analyses and generate graphs with insect herbivory data - regardless of whether the methods are appropriate for the data and regardless of whether the datasets are sufficiently complete to meet the assumptions of the methods. As shown here, the Chao1 estimator, a method that is particularly well-suited to handle the sparseness of insect herbivory datasets, rarely provides estimates of damage type diversity that are both precise enough to minimize the frequency of false negative results and accurate enough to contain the true, asymptotic value.

Moreover, asymptotic damage type diversity calculated through a combination of rarefaction and the Chao1 estimator is formulated as an unbiased estimator but is severely biased by sample size, presumably due to the exceptional sparsity of herbivory datasets. This finding highlights the need to regress estimators of insect herbivory against the number of leaves and damage types in raw datasets to verify that they are not biased by sampling effort.

Whereas size-based rarefaction and the Chao1 estimator present insurmountable limitations for insect herbivory data, coverage-based rarefaction holds the most promise for generating estimates of damage type diversity that are unbiased, and robust to leaf size and sample size. Combined with the herbivory index, which measures the intensity of insect herbivory, estimates of damage type diversity can be leveraged as the foundation of a theoretical ecospace. This ecospace holds the potential to address two overarching questions that remained unresolved for two decades. First is how to distinguish the minor variation in insect herbivory that inevitably occurs among assemblages from slightly different times or places (null hypothesized amount of variation) from the changes in insect herbivory that accompany major abiotic events or innovations in insect evolution (alternative hypothesis). Second is how to distinguish among abiotic causes (e.g., mass extinctions) 
and biotic causes (insect and plant evolution) of major changes in the amount of insect herbivory.

There are two ways to build upon the many fossil herbivory datasets amassed over the past few decades: collecting more data, and interrogating existing data to develop and refine analytical frameworks. By advancing the latter, a theoretical ecospace for insect herbivory will hopefully underscore the importance the former.

\section{ACKNOWLEDGEMENTS}

This contribution was made possible by the many paleontologists who have collected fossil plants and described the insect damage they contain, with John Anderson and Heidi Holmes particularly deserving of recognition here. Bárbara Cariglino, Mónica R. Carvalho, Michael P. Donovan, L. Alejandro Giraldo, Christian Müller, Manuel Robledo, Torsten Wappler, and Peter Wilf provided access to datasets. The Paleobotany Reading Group at Stanford University provided valuable discussion. We thank two anonymous reviewers for their very helpful feedback. S.R.S. received funding from the Coleman F. Fung Interdisciplinary Graduate Fellowship, Vice Provost of Graduate Education, Stanford University; from the Harriet Benson Fellowship Award, Department of Geological Sciences, Stanford University; and from the Winifred Goldring Award, Association of Women Geoscientists and Paleontological Society. 


\begin{tabular}{|c|c|c|c|c|c|}
\hline Assemblage & Leaves & DTs & Period & Age & Citation \\
\hline Birds River 111 & 7,106 & 35 & Triassic & Carnian & Labandeira et al. (2018) \\
\hline Greenvale 121 & 2,749 & 12 & Triassic & Carnian & Labandeira et al. (2018) \\
\hline Boesmanshkoek 112 & 1,058 & 2 & Triassic & Carnian & Labandeira et al. (2018) \\
\hline Cyphergat 111A & 5,499 & 26 & Triassic & Carnian & Labandeira et al. (2018) \\
\hline Kannaskop 111 & 2,114 & 11 & Triassic & Carnian & Labandeira et al. (2018) \\
\hline Telemachus Spruit 111 & 5,8 & 14 & Triassic & Carnian & Labandeira et al. (2018) \\
\hline Kommandantskop 111 & 1,096 & 8 & Triassic & Carnian & Labandeira et al. (2018) \\
\hline Vineyard 111 & 2,146 & 10 & Triassic & Carnian & Labandeira et al. (2018) \\
\hline Elandspruit 111 & 1,054 & 10 & Triassic & Carnian & Labandeira et al. (2018) \\
\hline Kraai I & 1,213 & 6 & Triassic & Carnian & Labandeira et al. (2018) \\
\hline Kraai River $111^{\mathrm{a}}$ & 1,780 & 8 & & Carnian & Labandeira et al. (2018) \\
\hline & 5,180 & 22 & & Carnian & Labandeira et al. (2018) \\
\hline & & 11 & & & Labandeira et al. (2018) \\
\hline Kroon $222^{\mathrm{a}}$ & 1,679 & 13 & & & \\
\hline Kroon 111A & & 5 & & & \\
\hline & & 4 & & & \\
\hline & & 12 & & & \\
\hline & & 17 & & & \\
\hline & & 9 & & & \\
\hline & & 17 & & & \\
\hline & & 27 & & & \\
\hline Elai & & 5 & & & \\
\hline iit 111B & & 18 & & & \\
\hline uit 111 & & 16 & & & \\
\hline & & 7 & & & \\
\hline $\mathrm{Mal}$ & & 6 & & & \\
\hline lley 213 & & 16 & & & \\
\hline naas 111 & & 36 & & & \\
\hline & & 9 & & & \\
\hline Qac & & 7 & & & \\
\hline & & 23 & & & \\
\hline & & 16 & & & \\
\hline and 111 & & 28 & & & \\
\hline & & 11 & & & Labandeira et al. (201 \\
\hline & & 12 & & & Labandeira et al. (201 \\
\hline & & 18 & & & Labandeira et al. (2018) \\
\hline Aasvoëlberg 411 & 12,398 & 39 & Triassic & Carnian & Labandeira et al. (2018) \\
\hline
\end{tabular}

Table 1: The assemblages with over 1,000 broadleaf specimens from Labandeira et al. (2018), collected from the Molteno formation by Anderson and Anderson (1983, 1985, 1989, 2003, 2008, 2017), that were analyzed

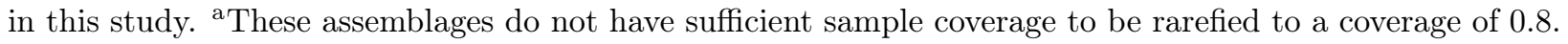




\begin{tabular}{|c|c|c|c|c|c|}
\hline Assemblage & Leaves & DTs & Period & Age & Citation \\
\hline Willershausen & 7,932 & 85 & Neogene & Piacenzian & Adroit et al. (2018) \\
\hline Lincang $^{\mathrm{a}}$ & 1,103 & 36 & Neogene & ?Tort.-Mess. & Zhang et al. (2018) \\
\hline Tröllatunga-Gautshamar & 1,069 & 17 & Neogene & Tortonian & Wappler and Grímsson (2016) \\
\hline Brjánslækur-Seljá & 1,613 & 29 & Neogene & Serravallian & Wappler and Grímsson (2016) \\
\hline Bílina-DSH & 2,233 & 54 & Neogene & Burdigalian & Knor et al. (2012) \\
\hline Břeštany-LCH & 1,181 & 28 & Neogene & Burdigalian & Knor et al. (2012) \\
\hline Rott & 2,474 & 55 & Paleogene & Chattian & Wappler (2010) \\
\hline Enspel & 1,622 & 39 & Paleogene & Chattian & Gunkel and Wappler (2015) \\
\hline MK-3 & 2,428 & 41 & Paleogene & Priabonian & Deng et al. (2020) \\
\hline Luckenau Clay Complex & 1,455 & 27 & Paleogene & Bart.-Pria. & Müller et al. (2017) \\
\hline Eckfeld maar & 6,748 & 78 & Paleogene & Lutetian & Wappler et al. (2012) \\
\hline Messel maar & 9,334 & 73 & Paleogene & Ypres.-Lutet. & Wappler et al. (2012) \\
\hline Republic & 1,019 & 34 & Paleogene & Ypresian & Labandeira (2002) \\
\hline Laguna del Hunco & 3,599 & 56 & Paleogene & Ypresian & Wilf et al. (2005) \\
\hline Wind River Interior & 1,755 & 40 & Paleogene & Ypresian & Currano et al. (2019) \\
\hline Fifteenmile Creek & 1,822 & 49 & Paleogene & Ypresian & Currano et al. (2010) \\
\hline South Fork of Elk Creek & 1,008 & 53 & Paleogene & Ypresian & Currano et al. (2008) \\
\hline Dead Platypus & 1,016 & 28 & Paleogene & Thanetian & Currano et al. (2010) \\
\hline Lur'd Leaves & 1,364 & 28 & Paleogene & Thanetian & Wilf et al. (2006) \\
\hline Kevin's Jerky & 1,423 & 25 & Paleogene & Selandian & Wilf et al. (2006) \\
\hline Palacio de los Loros 2 & 1,137 & 50 & Paleogene & Danian & Donovan et al. (2018) \\
\hline Castle Rock & 2,668 & 25 & Paleogene & Danian & Wilf et al. (2006) \\
\hline Mexican Hat & 2,220 & 34 & Paleogene & Danian & Donovan et al. (2014) \\
\hline Palacio de los Loros 1 & 1,089 & 41 & Paleogene & Danian & Donovan et al. (2018) \\
\hline Somebody's Garden & 1,528 & 32 & Cretaceous & Maastrichtian & Labandeira et al. (2002b) \\
\hline Kühwiesenkopf & 1,075 & 36 & Triassic & Anisian & Labandeira et al. (2016) \\
\hline Kayitou & 1,043 & 23 & Permian & Changhsingian & Liu et al. (2020) \\
\hline Bletterbach $^{\mathrm{a}, \mathrm{b}}$ & 1,193 & 14 & Permian & Wuch.-Chan. & Bernardi et al. (2017) \\
\hline Clouston Farm & 8,714 & 22 & Permian & Wuch.-Chan. & Prevec et al. (2009) \\
\hline Laguna Polina & 1,531 & 37 & Permian & $?$ & Cariglino (2018) \\
\hline Wuda ${ }^{a, b}$ & $\sim 10,000$ & 21 & Permian & Asselian & Feng et al. (2020) \\
\hline Williamson Drive & 1,830 & 39 & Permian & Asselian & Xu et al. (2018) \\
\hline Kinney & 1,992 & 9 & Pennsylvanian & Kasimovian & Donovan and Lucas (2021) \\
\hline
\end{tabular}

Table 2: The published assemblages with over 1,000 broadleaf specimens from sources other than Labandeira et al. (2018) that were analyzed in this study. ${ }^{\text {a }}$ These assemblages are not included in the sensitivity analysis presented in Figure S2 because damage type data are not available for each individual specimen. ${ }^{\mathrm{b}}$ These assemblages do not have sufficient sample coverage to be rarefied to a coverage of 0.8 . 


\begin{tabular}{|c|c|c|c|c|c|}
\hline Assemblage & Leaves & DTs & Period & Age & Citation \\
\hline Bernasso & 535 & 40 & Quaternary & Gelasian & Adroit et al. (2018) \\
\hline Berga & 534 & 25 & Neogene & Piacenzian & Adroit et al. (2018) \\
\hline Palo Pintado & 856 & 34 & Neogene & Mess.-Zanc. & Robledo et al. (2018) \\
\hline Hreðavatn-Stafholt & 678 & 23 & Neogene & Messinian & Wappler and Grímsson (2016) \\
\hline Skarðsströnd-Mókollsdalur & 524 & 21 & Neogene & Tortonian & Wappler and Grímsson (2016) \\
\hline San José & 384 & 9 & Neogene & Serravallian & Robledo et al. (2018) \\
\hline Selárdalur-Botn & 256 & 10 & Neogene & Langhian & Wappler and Grímsson (2016) \\
\hline Punta Basílica & 209 & 26 & Neogene & Aqui.-Lang. & Gandolfo and Zamaloa (2021) \\
\hline Güvem & 624 & 45 & Neogene & Burdigalian & Adroit et al. (2021) \\
\hline Hindon Maar & 466 & 78 & Neogene & Burdigalian & Möller et al. (2017) \\
\hline Quegstein & 404 & 13 & Paleogene & Rupel.-Chat. & Wappler (2010) \\
\hline MK-1 & 599 & 20 & Paleogene & Rupelian & Deng et al. (2020) \\
\hline Renardodden & 413 & 18 & Paleogene & Pria.-Rupel. & Wappler and Denk (2011) \\
\hline Bonanza & 894 & 26 & Paleogene & Lutetian & Wilf and Labandeira (1999) \\
\hline Wind River Edge & 908 & 33 & Paleogene & Ypresian & Currano et al. (2019) \\
\hline $\mathrm{PN}$ & 693 & 28 & Paleogene & Ypresian & Currano et al. (2010) \\
\hline Sourdough & 792 & 23 & Paleogene & Ypresian & Wilf et al. (2001) \\
\hline Cool Period & 491 & 25 & Paleogene & Ypresian & Currano et al. (2010) \\
\hline Level E & 336 & 19 & Paleogene & Ypresian & Azevedo Schmidt et al. (2019) \\
\hline Hubble Bubble & 994 & 39 & Paleogene & Than./Ypres. & Currano et al. (2008) \\
\hline Daiye Spa & 843 & 33 & Paleogene & Thanetian & Currano et al. (2008) \\
\hline Clarkforkian & 749 & 27 & Paleogene & Thanetian & Wilf et al. (2001) \\
\hline Cerrejón & 507 & 28 & Paleogene & Thanetian & Wing et al. (2009) \\
\hline Level C & 311 & 21 & Paleogene & Thanetian & Azevedo Schmidt et al. (2019) \\
\hline Skeleton Coast & 840 & 21 & Paleogene & Thanetian & Wilf et al. (2006) \\
\hline Bogotá & 955 & 90 & Paleogene & Sela.-Than. & Giraldo et al. (2021) \\
\hline Kolfjellet & 357 & 18 & Paleogene & Sela.-Than. & Wappler and Denk (2011) \\
\hline Haz-Mat & 757 & 18 & Paleogene & Selandian & Wilf et al. (2006) \\
\hline Persites Paradise & 963 & 22 & Paleogene & Selandian & Wilf et al. (2006) \\
\hline Menat & 938 & 39 & Paleogene & Selandian & Wappler et al. (2009) \\
\hline Las Flores & 568 & 42 & Paleogene & Danian & Donovan et al. (2018) \\
\hline Pyramid Butte & 655 & 17 & Paleogene & Danian & Labandeira et al. (2002b) \\
\hline Battleship & 461 & 31 & Cretaceous & Maastrichtian & Labandeira et al. (2002b) \\
\hline Dean Street & 709 & 32 & Cretaceous & Maastrichtian & Labandeira et al. (2002b) \\
\hline Lefipán East & 607 & 45 & Cretaceous & Maastrichtian & Donovan et al. (2018) \\
\hline Luten's 4H Hadrosaur & 426 & 26 & Cretaceous & Maastrichtian & Labandeira et al. (2002b) \\
\hline Camarena $^{\mathrm{a}}$ & 428 & 11 & Jurassic & Aalenian & Santos et al. (2021) \\
\hline Monte Agnello & 646 & 19 & Triassic & Ladinian & Labandeira et al. (2016) \\
\hline Dos Hermanos ${ }^{\mathrm{a}}$ & 359 & 16 & Permian & Wuch.-Chan. & Cariglino (2018) \\
\hline South Ash Pasture ${ }^{a}$ & 505 & 22 & Permian & Road.-Capit. & Maccracken and Labandeira (2020) \\
\hline Doña Ana Mts. & 215 & 4 & Permian & Artinskian & DiMichele et al. (2018) \\
\hline Colwell Creek Pond & 991 & 46 & Permian & Artinskian & Schachat et al. (2014) \\
\hline Laguna Lillo $^{\mathrm{a}}$ & 232 & 7 & Permian & Assel.-Kung. & Cariglino (2018) \\
\hline Beeman $^{\mathrm{a}}$ & 392 & 7 & Pennsylvanian & Kasim.-Gzhel. & Lucas et al. (2021) \\
\hline
\end{tabular}

Table 3: The assemblages analyzed in this study with $200-1,000$ broadleaf specimens. ${ }^{a}$ These assemblages do not have sufficient sample coverage to be rarefied to a coverage of 0.8 . 


\section{REFERENCES}

Ackerly, D., Knight, C., Weiss, S., Barton, K., and Starmer, K. (2002). Leaf size, specific leaf area and microhabitat distribution of chaparral woody plants: Contrasting patterns in species level and community level analyses. Oecologia, 130(3):449-457.

Adams, J. M., Ahn, S., Ainuddin, N., and Lee, M.-L. (2011). A further test of a palaeoecological thermometer: Tropical rainforests have more herbivore damage diversity than temperate forests. Review of Palaeobotany and Palynology, 164:60-66.

Adams, J. M., Brusa Anthony, A., Soyeong Ahn, A., and Ainuddin, A. N. (2010). Present-day testing of a paleoecological pattern: Is there really a latitudinal difference in leaf-feeding insect-damage diversity? Review of Palaeobotany and Palynology, 162(1):63-70.

Adams, J. M. and Zhang, Y. (2009). Is there more insect folivory in warmer temperate climates? A latitudinal comparison of insect folivory in eastern North America. Journal of Ecology, 97(5):933-940.

Adams, J. M., Zhang, Y., Basri, M., and Shukor, N. (2009). Do tropical forest leaves suffer more insect herbivory? A comparison of tropical versus temperate herbivory, estimated from leaf litter. Ecological Research, 24(6):1381-1392.

Adroit, B., Girard, V., Kunzmann, L., Terral, J.-F., and Wappler, T. (2018). Plant-insect interactions patterns in three European paleoforests of the late-Neogene - early-Quaternary. PeerJ, 6:e5075.

Adroit, B., Teodoridis, V., Güner, T. H., and Denk, T. (2021). Patterns of insect damage types reflect complex environmental signal in Miocene forest biomes of Central Europe and the Mediterranean. Global and Planetary Change, 199:103451.

Anderson, H. M. and Anderson, J. M. (2008). Molteno Ferns: Late Triassic Biodiversity in Southern Africa. Strelitzia, 21:1-258.

Anderson, H. M. and Anderson, J. M. (2017). Molteno sphenophytes: Late Triassic biodiversity in southern Africa. Evolutionary Studies Institute Monograph Series, 1:1-191, pls 1-180.

Anderson, J. M. and Anderson, H. M. (1983). Palaeoflora of Southern Africa: Molteno Formation (Triassic): Volume 1: Part 1. Introduction Part 2. Dicroidium. Balkema, Rotterdam.

Anderson, J. M. and Anderson, H. M. (1985). Palaeoflora of Southern Africa: Prodromus of South African Megafloras, Devonian to Lower Cretaceous. Balkema, Rotterdam. 
Anderson, J. M. and Anderson, H. M. (1989). Palaeoflora of Southern Africa: Molteno Formation (Triassic): Volume 2: Gymnosperms (Excluding Dicroidium). Balkema, Rotterdam.

Anderson, J. M. and Anderson, H. M. (2003). Heyday of the gymnosperms: Systematics and biodiversity of the Late Triassic Molteno fructifications. Strelitzia, 15:1-398.

Andrew, N. R. and Hughes, L. (2005). Herbivore damage along a latitudinal gradient: Relative impacts of different feeding guilds. Oikos, 108(1):176-182.

Anstett, D. N., Naujokaitis-Lewis, I., and Johnson, M. T. J. (2014). Latitudinal gradients in herbivory on Oenothera biennis vary according to herbivore guild and specialization. Ecology, 95(10):2915-2923.

Azevedo Schmidt, L. E., Dunn, R. E., Mercer, J., Dechesne, M., and Currano, E. D. (2019). Plant and insect herbivore community variation across the Paleocene-Eocene boundary in the Hanna Basin, southeastern Wyoming. PeerJ, 7:e7798.

Balisi, M. A. and Van Valkenburgh, B. (2020). Iterative evolution of large-bodied hypercarnivory in canids benefits species but not clades. Communications Biology, 3(1):1-9.

Bambach, R. K. (1983). Ecospace utilization and guilds in marine communities through the Phanerozoic. In Stehli, F. G., Tevesz, M. J. S., and McCall, P. L., editors, Biotic Interactions in Recent and Fossil Benthic Communities, volume 3, pages 719-746. Springer US, Boston, MA.

Bazzaz, F. A. (1990). The response of natural ecosystems to the rising global $\mathrm{CO}_{2}$ levels. Annual Review of Ecology and Systematics, 21:167-196.

Beck, A. L. and Labandeira, C. C. (1998). Early Permian insect folivory on a gigantopterid-dominated riparian flora from north-central Texas. Palaeogeography, Palaeoclimatology, Palaeoecology, 142:139-173.

Belcher, C. M., Mander, L., Rein, G., Jervis, F. X., Haworth, M., Hesselbo, S. P., Glasspool, I. J., and McElwain, J. C. (2010). Increased fire activity at the Triassic/Jurassic boundary in Greenland due to climate-driven floral change. Nature Geoscience, 3(6):426-429.

Bernardi, M., Petti, F. M., Kustatscher, E., Franz, M., Hartkopf-Fröder, C., Labandeira, C. C., Wappler, T., van Konijnenburg-van Cittert, J. H., Peecook, B. R., and Angielczyk, K. D. (2017). Late Permian (Lopingian) terrestrial ecosystems: A global comparison with new data from the low-latitude Bletterbach Biota. Earth-Science Reviews, 175(May):18-43.

Blüthgen, N. (2010). Why network analysis is often disconnected from community ecology: A critique and an ecologist's guide. Basic and Applied Ecology, 11(3):185-195. 
Blüthgen, N., Fründ, J., Vázquez, D. P., and Menzel, F. (2008). What Do Interaction Network Metrics Tell Us About Specialization and Biological Traits. Ecology, 89(12):3387-3399.

Boyce, C. K. and Zwieniecki, M. A. (2012). Leaf fossil record suggests limited influence of atmospheric $\mathrm{CO}_{2}$ on terrestrial productivity prior to angiosperm evolution. Proceedings of the National Academy of Sciences, 109(26):10403-10408.

Buck, L., Lambdin, P., Paulsen, D., Grant, J., and Saxton, A. (2005). Insect species associated with eastern hemlock in the Great Smoky Mountains National Park and environs. Journal of the Tennessee Academy of Science, 80(3-4):60-69.

Bush, A. M., Bambach, R. K., and Daley, G. M. (2007). Changes in theoretical ecospace utilization in marine fossil assemblages between the mid-Paleozoic and late Cenozoic. Paleobiology, 33(1):76-97.

Bush, A. M. and Novack-Gottshall, P. M. (2012). Modelling the ecological-functional diversification of marine Metazoa on geological time scales. Biology Letters, 8(1):151-155.

Cariglino, B. (2018). Patterns of insect-mediated damage in a Permian Glossopteris flora from Patagonia (Argentina). Palaeogeography, Palaeoclimatology, Palaeoecology, 507:39-51.

Carvalho, M. R., Wilf, P., Barrios, H., Windsor, D. M., Currano, E. D., Labandeira, C. C., and Jaramillo, C. A. (2014). Insect leaf-chewing damage tracks herbivore richness in modern and ancient forests. PLOS ONE, 9(5):e94950.

Chao, A. (1987). Estimating the population size for capture-recapture data with unequal catchability. Biometrics, 43(4):783-791.

Chao, A. (1989). Estimating population size for sparse data in capture-recapture experiments. Biometrics, 45(2):427-438.

Chao, A., Colwell, R. K., Lin, C.-W., and Gotelli, N. J. (2009). Sufficient sampling for asymptotic minimum species richness estimators. Ecology, 90(4):1125-1133.

Chao, A., Gotelli, N. J., Hsieh, T. C., Sander, E. L., Ma, K. H., Colwell, R. K., and Ellison, A. M. (2014). Rarefaction and extrapolation with Hill numbers: A framework for sampling and estimation in species diversity studies. Ecological Monographs, 84(1):45-67.

Chao, A. and Jost, L. (2012). Coverage-based rarefaction and extrapolation: Standardizing samples by completeness rather than size. Ecology, 93(12):2533-2547. 
Chen, M., Strömberg, C. A. E., and Wilson, G. P. (2019). Assembly of modern mammal community structure driven by Late Cretaceous dental evolution, rise of flowering plants, and dinosaur demise. Proceedings of the National Academy of Sciences of the United States of America, 116(20):9931-9940.

Chiu, C.-H., Wang, Y.-T., Walther, B. A., and Chao, A. (2014). An improved nonparametric lower bound of species richness via a modified good-turing frequency formula. Biometrics, 70(3):671-682.

Christenhusz, M. J. M. and Byng, J. W. (2016). The number of known plants species in the world and its annual increase. Phytotaxa, 261(3):201-217.

Colwell, R. K., Chao, A., Gotelli, N. J., Lin, S. Y., Mao, C. X., Chazdon, R. L., and Longino, J. T. (2012). Models and estimators linking individual-based and sample-based rarefaction, extrapolation and comparison of assemblages. Journal of Plant Ecology, 5(1):3-21.

Connell, J. H. (1971). On the role of natural enemies in preventing competitive exclusion in some marine animals and in rain forest trees. Dynamics of Populations, 298:312.

Cunningham, S. A., Summerhayes, B., and Westoby, M. (1999). Evolutionary divergences in leaf structure and chemistry, comparing rainfall and soil nutrient gradients. Ecological Monographs, 69(4):569-588.

Currano, E. D. (2009). Patchiness and long-term change in early Eocene insect feeding damage. Paleobiology, 35(4):484-498.

Currano, E. D., Labandeira, C. C., and Wilf, P. (2010). Fossil insect folivory tracks paleotemperature for six million years. Ecological Monographs, 80(4):547-567.

Currano, E. D., Laker, R., Flynn, A. G., Fogt, K. K., Stradtman, H., and Wing, S. L. (2016). Consequences of elevated temperature and $p \mathrm{CO}_{2}$ on insect folivory at the ecosystem level: Perspectives from the fossil record. Ecology and Evolution, 6(13):4318-4331.

Currano, E. D., Pinheiro, E. R. S., Buchwaldt, R., Clyde, W. C., and Miller, I. M. (2019). Endemism in Wyoming plant and insect herbivore communities during the early Eocene hothouse. Paleobiology, 45(3):421-439.

Currano, E. D., Wilf, P., Wing, S. L., Labandeira, C. C., Lovelock, E. C., and Royer, D. L. (2008). Sharply increased insect herbivory during the Paleocene-Eocene Thermal Maximum. Proceedings of the National Academy of Sciences of the United States of America, 105(6):1960-1964.

Deng, W., Su, T., Wappler, T., Liu, J., Li, S., Huang, J., Tang, H., Low, S. L., Wang, T., Xu, H., Xu, X., Liu, P., and Zhou, Z. (2020). Sharp changes in plant diversity and plant-herbivore interactions during the 
Eocene-Oligocene transition on the southeastern Qinghai-Tibetan Plateau. Global and Planetary Change, 194:103293.

Dilling, C., Lambdin, P., Grant, J., and Buck, L. (2007). Insect guild structure associated with eastern hemlock in the southern Appalachians. Environmental Entomology, 36(6):1408-1414.

DiMichele, W. A., Lucas, S. G., Chaney, D. S., Donovan, M. P., Kerp, H., Koll, R. A., and Looy, C. V. (2018). Early Permian flora, Doña Ana Mountains, southern New Mexico, with special consideration of taxonomic issues and arthropod damage. In Lucas, S. G. and Sullivan, R., editors, Fossil Record 6, volume 79 of New Mexico Museum of Natural History and Science Bulletin, pages 165-205. New Mexico Museum of Natural History and Science.

Ding, Q., Labandeira, C. C., Meng, Q., and Ren, D. (2015). Insect herbivory, plant-host specialization and tissue partitioning on mid-Mesozoic broadleaved conifers of Northeastern China. Palaeogeography, Palaeoclimatology, Palaeoecology, 440:259-273.

Ding, Q., Labandeira, C. C., and Ren, D. (2014). Biology of a leaf miner (Coleoptera) on Liaoningocladus boii (Coniferales) from the Early Cretaceous of northeastern China and the leaf-mining biology of possible insect culprit clades. Arthropod Systematics \& Phylogeny, 72(3):281-308.

Diserud, O. H. and Engen, S. (2000). A general and dynamic species abundance model, embracing the lognormal and the gamma models. The American Naturalist, 155(4):497-511.

Dmitriev, V. and Zherikin, V. (1988). Changes in the diversity of insect families from data of first and last occurrences. In Ponomarenko, A., editor, The Mesozoic-Cenozoic Crisis in the Evolution of Insects, pages 208-215. Academy of Sciences, Moscow.

Dobzhansky, T. (1950). Evolution in the tropics. American scientist, 38(2):209-221.

Donovan, M. P., Iglesias, A., Wilf, P., Labandeira, C. C., and Cúneo, N. R. (2017). Rapid recovery of Patagonian plant-insect associations after the end-Cretaceous extinction. Nature Ecology 83 Evolution, 1(1):0012.

Donovan, M. P., Iglesias, A., Wilf, P., Labandeira, C. C., and Cúneo, N. R. (2018). Diverse plant-insect associations from the latest Cretaceous and early Paleocene of Patagonia, Argentina. Ameghiniana, 55(3):303-338.

Donovan, M. P. and Lucas, S. G. (2021). Insect herbivory on the Late Pennsylvanian Kinney Brick Quarry flora, New Mexico, USA. In Lucas, S. G., DiMichele, W. A., and Allen, B. D., editors, Kinney Brick Quarry Lagerstatte, volume 84 of New Mexico Museum of Natural Science Bulletin, pages 193-207. 
Donovan, M. P., Wilf, P., Labandeira, C. C., Johnson, K. R., and Peppe, D. J. (2014). Novel insect leafmining after the end-Cretaceous extinction and the demise of Cretaceous leaf miners, Great Plains, USA. PLoS ONE, 9(7):e103542.

Dos Santos, T. B., De Souza Pinheiro, E. R., and Iannuzzi, R. (2020). First evidence of seed predation by arthropods from Gondwana and its early Paleozoic history (Rio Bonito Formation, Paraná Basin, Brazil). Palaios, 35(7):292-301.

Eiseman, C. (2019). Leafminers of North America. Self published e-book.

Feng, Z., Wang, J., Zhou, W.-M., Wan, M.-L., and Pšenička, J. (2020). Plant-insect interactions in the early Permian Wuda Tuff Flora, North China. Review of Palaeobotany and Palynology.

Filion, L., Payette, S., Robert, É. C., Delwaide, A., and Lemieux, C. (2006). Insect-induced tree dieback and mortality gaps in high-altitude balsam fir forests of northern New England and adjacent areas. Écoscience, $13(2): 275-287$.

Foster, D. R., Oswald, W. W., Faison, E. K., Doughty, E. D., and Hansen, B. C. S. (2006). A climatic driver for abrupt mid-Holocene vegetation dynamics and the hemlock decline in New England. Ecology, 87(12):2959-2966.

Frey, L., Rücklin, M., Korn, D., and Klug, C. (2018). Late Devonian and Early Carboniferous alpha diversity, ecospace occupation, vertebrate assemblages and bio-events of southeastern Morocco. Palaeogeography, Palaeoclimatology, Palaeoecology, 496:1-17.

Gandolfo, M. A. and Zamaloa, M. C. (2021). Southern high-latitude plant-insect interactions from the Miocene of Tierra del Fuego, Argentina. International Journal of Plant Sciences, pages 000-000.

Gerber, S. (2017). The geometry of morphospaces: Lessons from the classic Raup shell coiling model. Biological Reviews, 92(2):1142-1155.

Ghosh, A. K., Kar, R., and Chatterjee, R. (2015). Leaf galls on Dicroidium hughesii (Feistmantel) Lele from the Triassic of India - a new record. Alcheringa, 39(1):92-98.

Giraldo, L. A., Labandeira, C., Herrera, F., and Carvalho, M. (2021). Rich and specialized plant-insect associations in a Middle-Late Paleocene (58-60 Ma) neotropical rainforest (Bogotá Formation, Colombia). Ameghiniana, 58(2):75-99-75-99.

Givnish, T. J. (1987). Comparative studies of leaf form: Assessing the relative roles of selective pressures and phylogenetic constraints. New Phytologist, 106(s1):131-160. 
Good, I. J. (1953). The population frequencies of species and the estimation of population parameters. Biometrika, 40(3-4):237-264.

Gunkel, S. and Wappler, T. (2015). Plant-insect interactions in the upper Oligocene of Enspel (Westerwald, Germany), including an extended mathematical framework for rarefaction. Palaeobiodiversity and Palaeoenvironments, 95(1):55-75.

Hsieh, T. C., Ma, K. H., and Chao, A. (2016). iNEXT: An R package for rarefaction and extrapolation of species diversity (Hill numbers). Methods in Ecology and Evolution, 7(12):1451-1456.

Iannuzzi, R. and Labandeira, C. C. (2008). The oldest record of external foliage feeding and the expansion of insect folivory on land. Annals of the Entomological Society of America, 101(1):79-94.

Janzen, D. H. (1970). Herbivores and the number of tree species in tropical forests. The American Naturalist, 104(940):501-528.

Janzen, D. H. (1973). Host plants as islands. II. Competition in evolutionary and contemporary time. The American Naturalist, 107(958):786-790.

Jarzembowski, E. A. and Ross, A. J. (1996). Insect origination and extinction in the Phanerozoic. Geological Society of London, Special Publications, 102(1):65-78.

Jost, L. (2010). The relation between evenness and diversity. Diversity, 2(2):207-232.

Kaplan, I. and Denno, R. F. (2007). Interspecific interactions in phytophagous insects revisited: A quantitative assessment of competition theory. Ecology Letters, 10(10):977-994.

Knezevic, A. (2008). Overlapping confidence intervals and statistical significance. StatNews: Cornell University Statistical Consulting Unit, 73(1).

Knobbe, T. K. and Schaller, M. F. (2017). A tight coupling between atmospheric $p \mathrm{CO}_{2}$ and sea-surface temperature in the Late Triassic. Geology, 46(1):43-46.

Knope, M. L., Heim, N. A., Frishkoff, L. O., and Payne, J. L. (2015). Limited role of functional differentiation in in early diversification of animals. Nature Communications, 6:6455.

Knor, S., Prokop, J., Kvaček, Z., Janovský, Z., and Wappler, T. (2012). Plant-arthropod associations from the Early Miocene of the Most Basin in North Bohemia-Palaeoecological and palaeoclimatological implications. Palaeogeography, Palaeoclimatology, Palaeoecology, 321-322:102-112. 
Labandeira, C. C. (2002). Paleobiology of middle Eocene plant-insect associations from the Pacific Northwest: A preliminary report. Rocky Mountain Geology, 37(1):31-59.

Labandeira, C. C. (2006). The four phases of plant-arthropod associations in deep time. Geologica Acta, 4(4):409-438.

Labandeira, C. C. (2012). Evidence for outbreaks from the fossil record of insect herbivory. In Barbosa, P., Letourneau, D. K., and Agrawal, A. A., editors, Insect Outbreaks Revisited, chapter 13, pages 267-290. Blackwell Publishing Ltd., Hoboken, NJ.

Labandeira, C. C. (2021). Ecology and evolution of gall-inducing arthropods: The pattern from the terrestrial fossil record. Frontiers in Ecology and Evolution, 9:632449.

Labandeira, C. C., Anderson, J. M., and Anderson, H. M. (2018). Expansion of arthropod herbivory in Late Triassic South Africa: The Molteno Biota, Aasvoëlberg 411 site and developmental biology of a gall. In Tanner, L. H., editor, The Late Triassic World: Earth in a Time of Transition, pages 623-719. Springer International Publishing, Cham.

Labandeira, C. C. and Currano, E. D. (2013). The fossil record of plant-insect dynamics. Annual Review of Earth and Planetary Sciences, 41(1):287-311.

Labandeira, C. C., Dilcher, D. L., Davis, D. R., and Wagner, D. L. (1994). Ninety-seven million years of angiosperm-insect association: Paleobiological insights into the meaning of coevolution. Proceedings of the National Academy of Sciences of the United States of America, 91(25):12278-12282.

Labandeira, C. C., Johnson, K. R., and Lang, P. (2002a). A preliminary assessment of insect herbivory across the Cretaceous/Tertiary boundary: Extinction and minimal rebound. In Hartman, J., Johnson, K. R., and Nichols, D., editors, The Hell Creek Formation and the Cretaceous-Tertiary Boundary in the Northern Great Plains-An Integrated Continental Record at the End of the Cretaceous, number 361, pages 297-327. Geological Society of America Special Paper, Boulder, Colorado.

Labandeira, C. C., Johnson, K. R., and Wilf, P. (2002b). Impact of the terminal Cretaceous event on plant-insect associations. Proceedings of the National Academy of Sciences of the United States of America, 99(4):2061-2066.

Labandeira, C. C., Kustatscher, E., and Wappler, T. (2016). Floral assemblages and patterns of insect herbivory during the Permian to Triassic of northeastern Italy. PLoS ONE, 11:e0165205.

Labandeira, C. C. and Sepkoski, J. J. (1993). Insect diversity in the fossil record. Science, 261(5119):310-315. 
Labandeira, C. C., Tremblay, S. L., Bartowski, K. E., and VanAller Hernick, L. (2013). Middle Devonian liverwort herbivory and antiherbivore defence. New Phytologist, 200:247-258.

Labandeira, C. C., Wilf, P., Johnson, K. R., and Marsh, F. (2007). Guide to Insect (and Other) Damage Types on Compressed Plant Fossils (Version 3.0). Smithsonian Institution, Washington DC.

Laing, B. A., Mángano, M. G., Buatois, L. A., Narbonne, G. M., and Gougeon, R. C. (2019). A protracted Ediacaran-Cambrian transition: An ichnologic ecospace analysis of the Fortunian in Newfoundland, Canada. Geological Magazine, 156(9):1623-1630.

Li, L., Wang, Y., Kürschner, W. M., Ruhl, M., and Vajda, V. (2020). Palaeovegetation and palaeoclimate changes across the Triassic-Jurassic transition in the Sichuan Basin, China. Palaeogeography, Palaeoclimatology, Palaeoecology, 556:109891.

Liu, H.-Y., Wei, H.-B., Chen, J., Guo, Y., Zhou, Y., Gou, X.-D., Yang, S.-L., Labandeira, C., and Feng, Z. (2020). A latitudinal gradient of plant-insect interactions during the late Permian in terrestrial ecosystems? New evidence from Southwest China. Global and Planetary Change, 192:103248.

Lohman, B. K., Berner, D., and Bolnick, D. I. (2017). Clines arc through multivariate morphospace. The American Naturalist, 189(4):354-367.

Lucas, S. G. (2021). Nonmarine Mass Extinctions. Paleontological Research, 25(4).

Lucas, S. G., DiMichele, W. A., Krainer, K., Barrick, J. E., Vachard, D., P. Donovan, M., Looy, C., Kerp, H., and Chaney, D. S. (2021). The Pennsylvanian System in the Sacramento Mountains, New Mexico, USA: Stratigraphy, Petrography, Depositional Systems, Paleontology, Biostratigraphy and Geologic History. The Smithsonian Institution.

Ma, F.-J., Ling, C.-C., Ou-Yang, M.-S., Yang, G.-M., Shen, X.-P., and Wang, Q.-J. (2020). Plant-insect interactions from the Miocene (Burdigalian-Langhian) of Jiangxi, China. Review of Palaeobotany and Palynology, 275:104176.

MacArthur, R. H. (1969). Patterns of communities in the tropics. Biological Journal of the Linnean Society, $1(1-2): 19-30$.

Maccracken, S. A. (2020). Plant-Arthropod Associations from the Western Interior of North America during the Late Cretaceous. PhD thesis, University of Maryland, College Park, MD. 
Maccracken, S. A. and Labandeira, C. C. (2020). The Middle Permian South Ash Pasture assemblage of north-central Texas: Coniferophyte and gigantopterid herbivory and longer-term herbivory trends. International Journal of Plant Sciences, 181(3):342-362.

Martinez, A. J., Onchuru, T. O., Ingham, C. S., Sandoval-Calderón, M., Salem, H., Deckert, J., and Kaltenpoth, M. (2019). Angiosperm to Gymnosperm host-plant switch entails shifts in microbiota of the Welwitschia bug, Probergrothius angolensis (Distant, 1902). Molecular Ecology, 28(23):5172-5187.

Mattson, W. J. (1980). Herbivory in relation to plant nitrogen content. Annual Review of Ecology and Systematics, 11(1):119-161.

McElwain, J. C. and Punyasena, S. W. (2007). Mass extinction events and the plant fossil record. Trends in Ecology 83 Evolution, 22(10):548-557.

McGarigal, K., Cushman, S. A., and Stafford, S. (2013). Multivariate Statistics for Wildlife and Ecology Research. Springer.

McGhee, G. R. (2006). The concept of the theoretical morphospace. In The Geometry of Evolution: Adaptive Landscapes and Theoretical Morphospaces, pages 57-70. Cambridge University Press, Cambridge.

McLoughlin, S., Martin, S. K., and Beattie, R. (2015). The record of Australian Jurassic plant-arthropod interactions. Gondwana Research, 27:940-959.

McMurtrie, R. E., Norby, R. J., Medlyn, B. E., Dewar, R. C., Pepper, D. A., Reich, P. B., and Barton, C. V. M. (2008). Why is plant-growth response to elevated $\mathrm{CO}_{2}$ amplified when water is limiting, but reduced when nitrogen is limiting? A growth-optimisation hypothesis. Functional Plant Biology, 35(6):521.

Mills, B. J. W., Krause, A. J., Scotese, C. R., Hill, D. J., Shields, G. A., and Lenton, T. M. (2019). Modelling the long-term carbon cycle, atmospheric $\mathrm{CO} 2$, and Earth surface temperature from late Neoproterozoic to present day. Gondwana Research, 67:172-186.

Minter, N. J., Buatois, L. A., Mángano, M. G., Davies, N. S., Gibling, M. R., MacNaughton, R. B., and Labandeira, C. C. (2017). Early bursts of diversification defined the faunal colonization of land. Nature Ecology \& Evolution, 1:0175.

Moles, A. T., Bonser, S. P., Poore, A. G. B., Wallis, I. R., and Foley, W. J. (2011). Assessing the evidence for latitudinal gradients in plant defence and herbivory. Functional Ecology, 25(2):380-388.

Möller, A. L., Kaulfuss, U., Lee, D. E., and Wappler, T. (2017). High richness of insect herbivory from the early Miocene Hindon Maar crater, Otago, New Zealand. PeerJ, 5:e2985. 
Mondal, S. and Harries, P. J. (2016). Phanerozoic trends in ecospace utilization: The bivalve perspective. Earth-Science Reviews, 152:106-118.

Moreira, X., Abdala-Roberts, L., Parra-Tabla, V., and Mooney, K. A. (2015). Latitudinal variation in herbivory: Influences of climatic drivers, herbivore identity and natural enemies. Oikos, 124(11):14441452.

Müller, C., Wappler, T., and Kunzmann, L. (2017). Insect herbivory patterns in late Eocene coastal lowland riparian associations from central Germany. Palaeogeography, Palaeoclimatology, Palaeoecology, 491:170184.

Na, Y.-L., Sun, C.-L., Wang, H., Dilcher, D. L., Yang, Z.-Y., Li, T., and Li, Y.-F. (2018). Insect herbivory and plant defense on ginkgoalean and bennettitalean leaves of the Middle Jurassic Daohugou Flora from Northeast China and their paleoclimatic implications. Palaeoworld, 27(2):202-210.

Novack-Gottshall, P. M. (2007). Using a theoretical ecospace to quantify the ecological diversity of Paleozoic and modern marine biotas. Paleobiology, 33(2):273-294.

O'hara, R. B. (2005). Species richness estimators: How many species can dance on the head of a pin? Journal of Animal Ecology, 74(2):375-386.

Olszewski, T. D. (2004). A unified mathematical framework for the measurement of richness and evenness within and among multiple communities. Oikos, 104(2):377-387.

Orwig, D. A. and Foster, D. R. (1998). Forest response to the introduced hemlock woolly adelgid in southern New England, USA. The Journal of the Torrey Botanical Society, 125(1):60-73.

Oswald, W. W. (2016). Evaluating the role of insects in the middle-Holocene Tsuga decline. The Journal of the Torrey Botanical Society, 144(1):35-39.

Palmer, M. W. (1990). The estimation of species richness by extrapolation. Ecology, 71(3):1195-1198.

Pellmyr, O. (1992). Evolution of insect pollination and angiosperm diversification. Trends in Ecology \& Evolution, 7(2):46-49.

Pie, M. R. and Weitz, J. S. (2005). A null model of morphospace occupation. The American Naturalist, 166(1):E1-E13.

Pinheiro, E. R. S., Iannuzzi, R., and Duarte, L. D. S. (2016). Insect herbivory fluctuations through geological time. Ecology, 97(9):2501-2510. 
Prevec, R., Labandeira, C. C., Neveling, J., Gastaldo, R. A., Looy, C. V., and Bamford, M. (2009). Portrait of a Gondwanan ecosystem: A new late Permian fossil locality from KwaZulu-Natal, South Africa. Review of Palaeobotany and Palynology, 156(3-4):454-493.

Price, P. W., Bouton, C. E., Gross, P., McPheron, B. A., Thompson, J. N., and Weis, A. E. (1980). Interactions among three trophic levels: Influence of plants on interactions between insect herbivores and natural enemies. Annual Review of Ecology and Systematics, 11(1):41-65.

Puttick, M. N., Guillerme, T., and Wills, M. A. (2020). The complex effects of mass extinctions on morphological disparity. Evolution, 74(10):2207-2220.

Ramírez-Barahona, S., Sauquet, H., and Magallón, S. (2020). The delayed and geographically heterogeneous diversification of flowering plant families. Nature Ecology E Evolution, 4:1232-1238.

Raup, D. M. (1967). Geometric analysis of shell coiling: Coiling in ammonoids. Journal of Paleontology, $41(1): 43-65$.

Reich, P. B., Hobbie, S. E., and Lee, T. D. (2014). Plant growth enhancement by elevated $\mathrm{CO}_{2}$ eliminated by joint water and nitrogen limitation. Nature Geoscience, 7(12):920-924.

Robledo, J. M., Pinheiro, E. R. S., Gnaedinger, S. C., and Wappler, T. (2018). Plant-insect interactions on dicots and ferns from the Miocene of Argentina. Palaios, 33(7):338-352.

Ruhl, M. and Kürschner, W. M. (2011). Multiple phases of carbon cycle disturbance from large igneous province formation at the Triassic-Jurassic transition. Geology, 39(5):431-434.

Salazar, D. and Marquis, R. J. (2012). Herbivore pressure increases toward the equator. Proceedings of the National Academy of Sciences, 109(31):12616-12620.

Santos, A. A., Sender, L. M., Wappler, T., Engel, M. S., and Diez, J. B. (2021). A Robinson Crusoe story in the fossil record: Plant-insect interactions from a Middle Jurassic ephemeral volcanic island (Eastern Spain). Palaeogeography, Palaeoclimatology, Palaeoecology, 583:110655.

Schachat, S. R., Labandeira, C. C., and Chaney, D. S. (2015). Insect herbivory from early Permian Mitchell Creek Flats of north-central Texas: Opportunism in a balanced component community. Palaeogeography, Palaeoclimatology, Palaeoecology, 440:830-847.

Schachat, S. R., Labandeira, C. C., Gordon, J., Chaney, D., Levi, S., Halthore, M. N., and Alvarez, J. (2014). Plant-insect interactions from Early Permian (Kungurian) Colwell Creek Pond, north-central 
Texas: The early spread of herbivory in riparian environments. International Journal of Plant Sciences, 175(8):855-890.

Schachat, S. R., Labandeira, C. C., and Maccracken, S. A. (2018). The importance of sampling standardization for comparisons of insect herbivory in deep time: A case study from the late Palaeozoic. Royal Society Open Science, 5(3):171991.

Schachat, S. R., Maccracken, S. A., and Labandeira, C. C. (2020). Sampling fossil floras for the study of insect herbivory: How many leaves is enough? Fossil Record, 23(1):15-32.

Scott, A. C., Stephenson, J., and Chaloner, W. G. (1992). Interaction and coevolution of plants and arthropods during the Palaeozoic and Mesozoic. Philosophical Transactions of the Royal Society of London. Series B: Biological Sciences, 335(1274):129-165.

Shaw, M. R., Zavaleta, E. S., Chiariello, N. R., Cleland, E. E., Mooney, H. A., and Field, C. B. (2002). Grassland responses to global environmental changes suppressed by elevated $\mathrm{CO}_{2}$. Science, 298(5600):1987-1990.

Simard, I., Morin, H., and Potelle, B. (2002). A new paleoecological approach to reconstruct long-term history of spruce budworm outbreaks. Canadian Journal of Forest Research, 32(3):428-438.

Smith, D. M. (2008). A comparison of plant-insect associations in the middle Eocene Green River Formation and the upper Eocene Florissant Formation and their climatic implications. Geological Society of America Special Paper, 435(303):89-103.

Smith, E. P. and van Belle, G. (1984). Nonparametric estimation of species richness. Biometrics, 40(1):119129.

Smith, F. A., Brown, J. H., and Valone, T. J. (1997). Path analysis: A critical evaluation using long-term experimental data. The American Naturalist, 149(1):29-42.

Soltis, P. S. and Soltis, D. E. (2004). The origin and diversification of angiosperms. American Journal of Botany, 91(10):1614-1626.

Tamme, R., Hiiesalu, I., Laanisto, L., Szava-Kovats, R., and Pärtel, M. (2010). Environmental heterogeneity, species diversity and co-existence at different spatial scales. Journal of Vegetation Science, 21(4):796-801.

Turcotte, M. M., Thomsen, C. J. M., Broadhead, G. T., Fine, P. V. A., Godfrey, R. M., Lamarre, G. P. A., Meyer, S. T., Richards, L. A., and Johnson, M. T. J. (2014). Percentage leaf herbivory across vascular plant species. Ecology, 95(3):788-788. 
Valentine, J. W. (1969). Patterns of taxonomic and ecological structure of the shelf benthos during Phanerozoic time. Palaeontology, 12(4):684-709.

van Veen, F. F., Morris, R. J., and Godfray, H. C. J. (2006). Apparent competition, quantitative food webs, and the structure of phytophagous insect communities. Annual Review of Entomology, 51(1):187-208.

Wagner, S. M., Martinez, A. J., Ruan, Y.-M., Kim, K. L., Lenhart, P. A., Dehnel, A. C., Oliver, K. M., and White, J. A. (2015). Facultative endosymbionts mediate dietary breadth in a polyphagous herbivore. Functional Ecology, 29(11):1402-1410.

Wappler, T. (2010). Insect herbivory close to the Oligocene-Miocene transition-A quantitative analysis. Palaeogeography, Palaeoclimatology, Palaeoecology, 292(3-4):540-550.

Wappler, T., Currano, E. D., Wilf, P., Rust, J., and Labandeira, C. C. (2009). No post-Cretaceous ecosystem depression in European forests? Rich insect-feeding damage on diverse middle Palaeocene plants, Menat, France. Proceedings of the Royal Society B: Biological Sciences, 276:4271-4277.

Wappler, T. and Denk, T. (2011). Herbivory in early Tertiary Arctic forests. Palaeogeography, Palaeoclimatology, Palaeoecology, 310(3-4):283-295.

Wappler, T. and Grímsson, F. (2016). Before the 'Big Chill': Patterns of plant-insect associations from the Neogene of Iceland. Global and Planetary Change, 142:73-86.

Wappler, T., Kustatscher, E., and Dellantonio, E. (2015). Plant-insect interactions from Middle Triassic (late Ladinian) of Monte Agnello (Dolomites, N-Italy) - Initial pattern and response to abiotic environmental perturbations. PeerJ, 3:e921.

Wappler, T., Labandeira, C. C., Rust, J., Frankenhäuser, H., and Wilde, V. (2012). Testing for the effects and consequences of mid Paleogene climate change on insect herbivory. PLoS ONE, 7(7).

White, D. A. (1993). Relationships between foliar number and the cross-sectional areas of sapwood and annual rings in red oak (Quercus rubra) crowns. Canadian Journal of Forest Research, 23(7):1245-1251.

Wiedl, T., Harzhauser, M., Kroh, A., Ćorić, S., and Piller, W. E. (2013). Ecospace variability along a carbonate platform at the northern boundary of the Miocene reef belt (Upper Langhian, Austria). Palaeogeography, Palaeoclimatology, Palaeoecology, 370:232-246.

Wilf, P. and Labandeira, C. C. (1999). Response of plant-insect associations to Paleocene-Eocene warming. Science, 284(5423):2153-2156. 
Wilf, P., Labandeira, C. C., Johnson, K. R., Coley, P. D., and Cutter, A. D. (2001). Insect herbivory, plant defense, and early Cenozoic climate change. Proceedings of National Academy of Sciences of the United States of America, 98(11):6221-6226.

Wilf, P., Labandeira, C. C., Johnson, K. R., and Cuneo, N. R. (2005). Richness of plant-insect associations in Eocene Patagonia: A legacy for South American biodiversity. Proceedings of National Academy of Sciences of the United States of America, 102(25):8944-8948.

Wilf, P., Labandeira, C. C., Johnson, K. R., and Ellis, B. (2006). Decoupled plant and insect diversity after the end-Cretaceous extinction. Science, 313(5790):1112-1115.

Will, T., Furch, A. C., and Zimmermann, M. R. (2013). How phloem-feeding insects face the challenge of phloem-located defenses. Frontiers in Plant Science, 4:336.

Wilson, J. P. and Knoll, A. H. (2010). A physiologically explicit morphospace for tracheid-based water transport in modern and extinct seed plants. Paleobiology, 36(2):335-355.

Wing, S. L., Herrera, F., Jaramillo, C. A., Gómez-Navarro, C., Wilf, P., and Labandeira, C. C. (2009). Late Paleocene fossils from the Cerrejón Formation, Colombia, are the earliest record of Neotropical rainforest. Proceedings of the National Academy of Sciences of the United States of America, 106(44):18627-18632.

Xiao, L., Labandeira, C., Dilcher, D., and Ren, D. (2021). Florivory of Early Cretaceous flowers by functionally diverse insects: Implications for early angiosperm pollination. Proceedings of the Royal Society B: Biological Sciences, 288(1953):20210320.

Xu, Q., Jin, J., and Labandeira, C. C. (2018). Williamson Drive: Herbivory on a north-central Texas flora of latest Pennsylvanian age shows discrete component community structure, expansion of piercing and sucking, and plant counterdefenses. Review of Palaeobotany and Palynology, 251:28-72.

Zeebe, R. E. and Lourens, L. J. (2019). Solar System chaos and the Paleocene-Eocene boundary age constrained by geology and astronomy. Science, 365(6456):926-929.

Zhang, S.-H., Chen, T.-Y., Zeng, X., Yu, Y., Zhang, Y., and Xie, S.-P. (2018). Plant-insect associations from the upper Miocene of Lincang, Yunnan, China. Review of Palaeobotany and Palynology, 259:55-62.

Zhang, Y., Adams, J. M., and Zhao, D. (2011). Does insect folivory vary with latitude among temperate deciduous forests? Ecological Research, 26:377-383. 


\section{SuPPlemental MATERiAL}

\subsection{DifFiculties IN ESTIMATING DAMAGE TYPE DIVERSITY}

The differences in sampling intensity among Colwell Creek Pond and Mitchell Creek Flats pose an insurmountable obstacle to estimating true damage type diversity with raw or rarefied data. Rarefaction curves that include the dominant broadleaf plant taxa from both assemblages show that the estimate of higher damage type diversity for Colwell Creek Pond cannot be disentangled from the disparities in the amount of surface area examined (Figure S1A). If the damage type diversities tallied at each assemblage, 45 at Colwell Creek Pond and 19 at Mitchell Creek Flats, are interpreted at face value, the resulting conclusion that former contains greater damage type diversity is based entirely on an artifact of uneven sampling. However, even when the role of sampling completeness is taken into account, the overlapping confidence intervals complicate estimates of whether greater sampling would reveal significant differences in damage type diversity among the two assemblages (Knezevic, 2008).

The unreliability of diversity estimates derived from incompletely sampled assemblages is further underscored by the variability of estimated damage type diversity at Colwell Creek Pond when rarefaction curves are calculated with leaves from this locality that are randomly sampled only to the amount of surface area seen at Mitchell Creek Flats (Figure S1B-D). In other words, the difficulty of extrapolating damage type diversity at Mitchell Creek Flats for the amount of leaf area sampled from Colwell Creek Pond is due not only to the uncertainty surrounding damage type diversity beyond the amount of leaf area available, but also to the uncertainty surrounding the reliability of the damage type diversity estimated for Mitchell Creek Flats at the amount of leaf area that has been examined for this assemblage. Comparisons of damage type diversity, therefore, require a method such as rarefaction to control for differences in sampling completeness, and require fairly complete sampling of all localities - which can be difficult to achieve due to both the availability of fossil material and the investigator effort required.

The difficulty of estimating damage type diversity in light of sampling incompleteness is further compounded by the unavailability of surface area data for nearly all assemblages examined thus far (Schachat et al., 2018). Because leaf size varies so widely, two assemblages can have equivalent numbers of damage types per $400 \mathrm{~cm}^{2}$ of leaf surface area while having widely different numbers of damage types per 400 leaves. Variable leaf surface area can complicate, if not invalidate, attempts to use damage type data to discern macroevolutionary and macroecological patterns. For example, the amount of surface area per leaf available to insect herbivores has changed through time because gymnosperms and angiosperms have different average leaf sizes. As another example, whereas heightened levels of insect herbivory in the tropics 
form the basis of various biogeographical theories (Dobzhansky, 1950; MacArthur, 1969; Janzen, 1970; Connell, 1971), the magnitude of the latitudinal variability in herbivory is not entirely understood and depends considerably on the metric used (Anstett et al., 2014; Andrew and Hughes, 2005; Adams et al., 2011, 2009; Zhang et al., 2011; Adams and Zhang, 2009; Adams et al., 2010; Salazar and Marquis, 2012; Moreira et al., 2015; Moles et al., 2011). And because plants in wet biomes tend to have larger leaves (Ackerly et al., 2002; Cunningham et al., 1999; Givnish, 1987), rarefaction curves that are scaled by number of leaves rather than amount of leaf surface area may confound increased damage type diversity in wet tropical forests with increased leaf size in these habitats.

In addition to subsampling techniques such as rarefaction, a number of population estimators hold the potential to calculate true (asymptotic) damage type diversity and corresponding confidence intervals from datasets of varying levels of completeness (Chao, 1987; Chiu et al., 2014; O'hara, 2005; Palmer, 1990; Smith and van Belle, 1984). Of these, the Chao1 estimator is particularly well-suited to sparse datasets (Chao, 1989). However, these estimators follow the same pattern seen in rarefaction curves of steeply increasing estimates of diversity at low levels of sampling completeness (Chao et al., 2009). One might hope that the Chao1 estimator would behave like estimates of the herbivory index, with confidence intervals that contain the true value even when sampling is very incomplete and then narrowing more closely around the true value as sampling becomes more complete. However, this often is not the case. An analysis of plant assemblages for which at least 1,000 broadleaf specimens have been examined for insect herbivory (Tables 1, 2) shows that confidence intervals are deceptively narrow when sampling is insufficiently complete to capture the true value of damage type diversity (Figure S2). As sampling increases, the confidence intervals are more likely to contain an accurate result but often widen so much that false negative results become inevitable (Figure S2).

Whereas neither rarefaction nor the Chao1 estimator provide sufficient accuracy and precision to estimate damage type diversity, they have the potential to work far better in concert. The combination of rarefaction and Hill numbers (Chao et al., 2014), a family of metrics to which the Chaol estimator belongs, was an extension of advances in the extrapolation of rarefaction curves (Colwell et al., 2012) and in rarefaction based on sampling completeness rather than sample size (Chao and Jost, 2012). The Chaol estimator return an identical point estimates and confidence intervals for asymptotic diversity for a given frequency of damage type occurrences regardless of whether those damage type occurrences are spread out over 10 or 100,000 leaves. But, unlike the Chao1 estimator, rarefaction has the advantage of taking sampling completeness into account while generating diversity estimates. Unlike rarefaction, the Chaol estimator has the advantage of robustness to differences in leaf size and fragmentation because this metric estimates true, asymptotic diversity rather than diversity at a particular level of incomplete sampling. The method of Chao et al. (2014) 
possesses both of these advantages and is implemented in the R package iNEXT (Hsieh et al., 2016).

However, the method of Chao et al. (2014) yields estimates of asymptotic damage type diversity that are biased by the number of leaves sampled. This is probably because of the extreme sparsity of damage type occurrence datasets combined with the large quantity of damage types that are only observed once. The sensitivity of this method to sampling completeness can be seen when comparing the rarefaction curves for assemblages with over 7,000 leaves examined to extrapolated rarefaction curves generated after subsampling each assemblage down to 1,000 or 2,000 leaves (Figure S3). 2,000 leaves are rarely sufficient to extrapolate the complete rarefaction curve, and 1,000 leaves are sufficient for only one assemblage, Willershausen (Adroit et al., 2018). With 1,000 leaves, these extrapolated rarefaction curves level off far too quickly - and even for Willershausen, the one assemblage that does not follow this pattern, the $95 \%$ confidence interval is much too wide to permit the detection of significant differences in damage type diversity among most assemblages.

\subsection{THE UNRELIABILITY OF EXTRAPOLATED DIVERSITY ESTIMATES GENERATED WITH COVERAGE-BASED RAREFACTION}

To evaluate whether rarefied damage type diversity at a sample coverage of 0.8 can be extrapolated from datasets that do not reach this level of coverage, we used an iterative subsampling procedure. Leaves were subsampled from the pre-angiosperm assemblage with the largest number of leaves examined, Aasvoëlberg 411 (Labandeira et al., 2018), and the angiosperm assemblage with the largest number of leaves examined, Willershausen (Adroit et al., 2018). This procedure was repeated 3,000 times for each assemblage to ensure that a wide range of levels of sample coverage are represented among the subsampled datasets. For each subsampled dataset, we extrapolated rarefied damage type diversity to a sample coverage of 0.8 . The results of this procedure (Figure S4) show that the accuracy of extrapolated estimates of damage type diversity does increase with sample coverage, but these extrapolated estimates are never accurate enough to inspire any confidence. Therefore, we do not recommend extrapolating estimates of damage type diversity for assemblages with a sample coverage below 0.79 .

\subsection{EVAluation OF OTHER MEtrics}

The ecological literature contains a variety of complex metrics for the evaluation of trophic interactions. With paleontological data, and especially paleontological data from a clade with a history of biased collecting (Gunkel and Wappler, 2015), a fundamental question is whether the data at hand are sufficient to yield robust results when analyzed with more complex techniques.

Both plants and their damage types follow a dominance-diversity distribution that approximates a 
lognormal or gamma distribution (Figure S5), as do nearly all other biotic communities (Diserud and Engen, 2000). In a typical floral assemblage, the majority of plant hosts and damage types are rare.

Generating a standardized estimate of floral or damage type diversity at a given assemblage through rarefaction is a relatively simple matter of subsampling the more abundant taxa in a consistent fashion. Estimating relationships among plant hosts and damage types, however-for example, estimating the proportion of damage types on the second-most abundant plant host which also occur on the most abundant plant host - is a far more complex matter, and thus is far more sensitive to sample size. A single tree can grow thousands of leaves in a single year (White, 1993), but it is uncommon for thousands of leaves from a single fossil assemblage to be examined for insect herbivory (Tables 1 and 2). We are not sure if all fossil leaf material ever examined for the herbivory index contains more or less leaf surface area than a single elm tree.

Therefore, whereas the amount of sampling typically seen in studies of fossil herbivory is likely sufficient to determine whether the most common damage type at an assemblage occurs on the most common plant host at the assemblage, this amount of sampling is probably not sufficient to determine whether the twentiethmost-common damage type occurs on the twentieth-most-common plant host. The absence of the twentiethmost-common damage type on the twentieth-most-common plant host may indicate that this particular interaction did not occur in the community represented by the fossil assemblage, but can just as easily indicate that sampling is not sufficient to document this interaction.

To evaluate the reliability of complex metrics of insect herbivory calculated for fossil assemblages, we conducted two iterative subsampling routines with data from the pre-angiosperm assemblage with the largest number of leaves examined, Aasvoëlberg 411 (Labandeira et al., 2018), and the angiosperm assemblage with the largest number of leaves examined, Willershausen (Adroit et al., 2018). In both routines, we subsampled 1,000 leaves per iteration and iterated this procedure 1,000 times. For the first routine, we calculated the proportion of damage types occurring on the second-most-abundant plant host that also occur on the most abundant plant host. (This is perhaps the simplest metric of the nestedness of damage type communities among the plant hosts at an assemblage.) For the second routine, we divided the number of leaves belonging to the second-most-abundant plant host by the number of leaves belonging to the most abundant plant host. (The simplicity of this metric is emblematic of the metrics commonly used in the study of fossil herbivory.)

The results of these subsampling routines indicate that, whereas the dominance-diversity structure of the plant hosts within an assemblage is a valid and reliable metric (Figure S6B), the nestedness of damage type communities among individual plant hosts is not (Figure S6A). No sensitivity analyses are needed to demonstrate the impossibility of determining with any certainty whether the twentieth-most-common damage type at an assemblage is truly absent from the twentieth-most-common plant host-as opposed to 
evading detection due to the number of leaves examined. One could argue that this sort of failure of detection will be shared across all assemblages and therefore will not bias comparisons among assemblages. However, our sensitivity analysis demonstrates that even the very simplest measurement of damage type nestedness (the degree of nestedness among the two most abundant plant hosts) is hopelessly unreliable with 1,000 leaves.

Some analytical trends in paleobiology follow a boom-bust cycle in which a technique increases in popularity, perhaps due to positive connotations associated with its complexity, only to fall out of favor when its reliability, validity, and interpretability come into question (Smith et al., 1997). Our results indicate that the complexity of techniques that associate particular damage types with particular host plants, impressive as they may seem, require far more complete sampling than can be expected from studies of insect herbivory on fossil leaves.

These results also have implications for quantifying host specificity. At present, it is customary to rank each damage type within an assemblage by its host specificity on a discrete scale of generalist (1), intermediate specificity (2), or specialized (3). To avoid misinterpreting artifacts of incomplete sampling as biological phenomena, these rankings are only assigned to damage types that occur on three or more plant specimens. However, the findings presented in this section raise the question of whether three occurrences of a damage type are sufficient to determine its host specificity, particularly if a damage type is classified as specialized because all three of its occurrences are on the most abundant plant host at the assemblage.

\subsection{RARE DAMAGE TYPES AND A COMPARISON OF ANGIOSPERM- AND NON-ANGIOSPERM-DOMINATED ASSEMBLAGES}

With size-based rarefaction, one could argue that higher damage type diversities in angiosperm-dominated floras might become apparent at higher sample sizes. An analogous argument for coverage-based rarefaction is that higher damage type diversities in angiosperm-dominated floras might become apparent at higher levels of sample coverage. To evaluate this possibility, we repeated all coverage-based rarefaction analyses by rarefying to a sample coverage of 0.9 instead of 0.8 . This higher level of sample coverage incorporates a greater number of rare damage types in diversity estimates, thus constituting a sensitivity analysis of whether the similar damage type diversities estimated for Permian and Cenozoic assemblages in Figure 5 are attributable to the level of sample coverage to which the assemblages were rarefied.

For each assemblage we calculated the difference in damage type diversity when rarefied to a sampling coverage of 0.8 of 0.9 (Figure S7). We found that the differences are smallest for the Molteno assemblages listed in Table 1, which contain relatively low damage type diversities. Although far more 
angiosperm-dominated assemblages have been evaluated for insect herbivory than non-angiosperm-dominated assemblages outside of the Molteno Formation, the extent to which estimated damage type diversity differs with sample coverage is similar among these two categories. Of note, when sample coverage increases from 0.8 to 0.9 , the four assemblages with the greatest increase in estimated damage type diversity are the Hindon Maar, Eckfeld, Messel, and Bogotá assemblages, all of which are angiosperm-dominated and contain high damage type diversities. To discern whether this great increase in damage type diversity with heightened sample coverage is truly unique to angiosperm-dominated assemblages, far more non-angiosperm-dominated assemblages will need to be evaluated for insect herbivory.

Insect herbivory from these four assemblages was described within the last ten years (Wappler et al., 2012; Möller et al., 2017; Giraldo et al., 2021). Estimates of damage type diversity may be biased toward assemblages that have been described most recently under a scenario in which existing damage types are have increased in number (Dos Santos et al., 2020; Xiao et al., 2021). However, Giraldo et al. (2021) found that this is not the case: a more conservative approach toward splitting damage types does not yield a noticeable decrease in damage type diversity as standardized through rarefaction.

\subsection{THE NUMBER OF ITERATIONS NEEDED FOR RESAMPLING PROCEDURES}

To determine the number of iterations needed for the resampling procedures discussed in "Evaluating other potential dimensions of an ecospace for herbivory," we iteratively performed our suggested resampling routine for quantifying uncertainty surrounding the offset between the prevalence of each plant host and the prevalence of insect damage on it. For this procedure we used data from the Colwell Creek Pond assemblage (Schachat et al., 2014) because surface area measurements are available. We found that the width of the $84 \%$ confidence interval varies minimally whether 100 or 100,000 iterations of the resampling routine are performed, but stabilizes around 5,000 iterations (Figure S8). Therefore, we recommend that future studies use 5,000 resampling iterations to generate confidence intervals.

\subsection{CRITERIA FOR INCLUSION OF LEAVES AND DAMAGE TYPES}

As noted in the main text, C.C. Labandeira employs a wide definition of "foliage" that includes needles, liverworts, phyllids, photosynthetic wings of seeds, and even flattened horsetail axes whereas S.R. Schachat employs a narrower definition restricted to multi-veined broad leaves and leaves with a defined midvein. (Workers who study angiosperm assemblages typically examine leaves that are at least $50 \%$ complete. No specimens were removed from the raw datasets for any of the angiosperm-dominated assemblages analyzed 
here.) When deciding which specimens from published datasets (Prevec et al., 2009; Cariglino, 2018; Labandeira et al., 2018; Liu et al., 2020; Bernardi et al., 2017) to include in the analyses presented here, we employed a compromise definition that excludes needles, liverworts, phyllids, photosynthetic wings of seeds, and flattened horsetail axes but includes scale leaves.

The raw data for the Williamson Drive assemblage (Xu et al., 2018) preclude determinations of whether many of the individual specimens represent, or at least contain, broadleaf foliage. Therefore, the plant hosts from this assemblage included here are the five foliage types that were included in NMDS plot in the original publication: Sigillariophyllum leaves, Pseudomariopteris cordato-ovata, Annularia carinata, Lilpopia raciborskii, and Macroneuropteris scheuchzeri.

The data for the Wuda flora (Feng et al., 2020) do not include assignments of damage types. Therefore, damage types were tallied based on the descriptions in the text of the article. An exact count of broadleaf specimens was unavailable due to the vast number of specimens examined. Because of the sparsity of insect damage at Wuda, the amount of sample coverage for this entire dataset is 0.675 - well short of the threshold used here, 0.8. Our decisions about the Wuda plant taxa, therefore, are inconsequential, as this assemblage cannot be included in Figure 5.

The description of herbivory at the Lincang assemblage (Zhang et al., 2018) includes a number of unrecognizable damage types. Because the abstract of Zhang et al. (2018) contains a count of damage types that is restricted to those with numbers assigned in the Damage Guide (Labandeira et al., 2007), we followed the authors' lead and included only those damage types in our analysis.
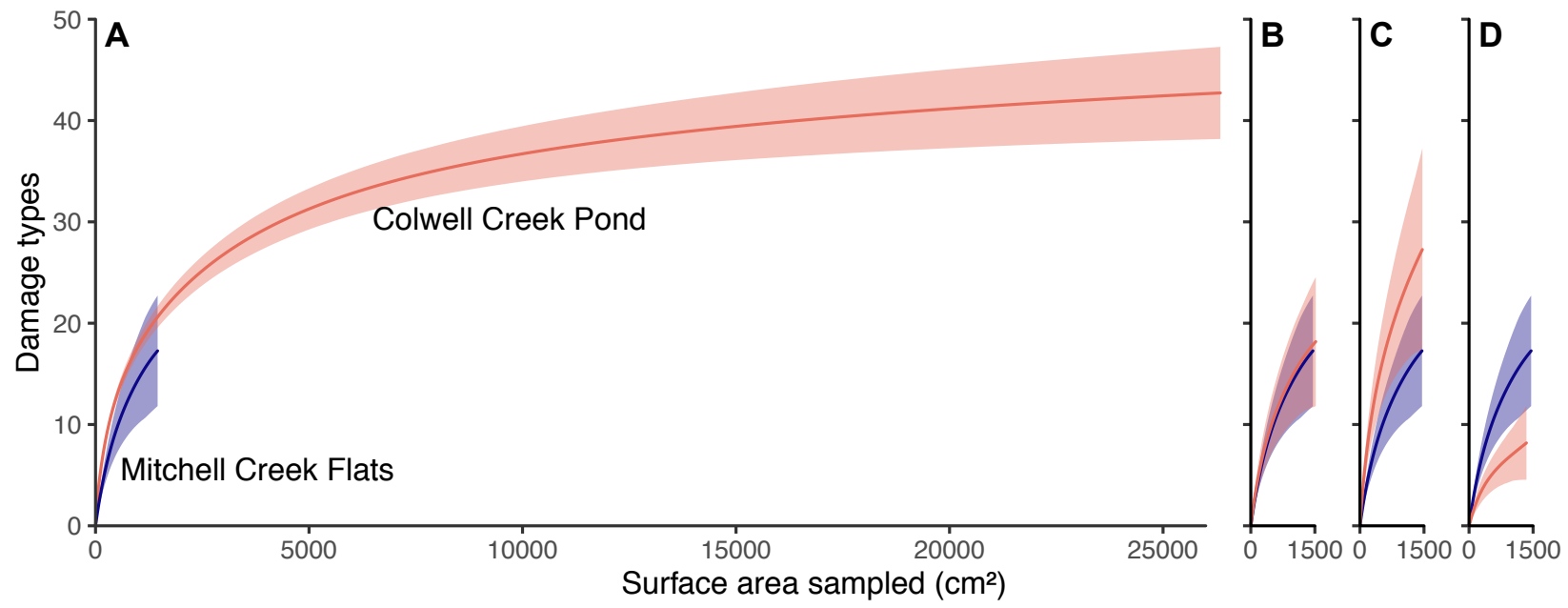

Figure S1: Rarefaction curves for two very similar assemblages: Colwell Creek Pond and Mitchell Creek Flats. A shows the rarefaction curves for all data from both assemblages. In $\mathbf{B}$ through $\mathbf{D}$, the rarefaction curves for Colwell Creek Pond are calculated from a randomly subsampled set of leaves with nearly equal surface area to that measured at Mitchell Creek Flats. 


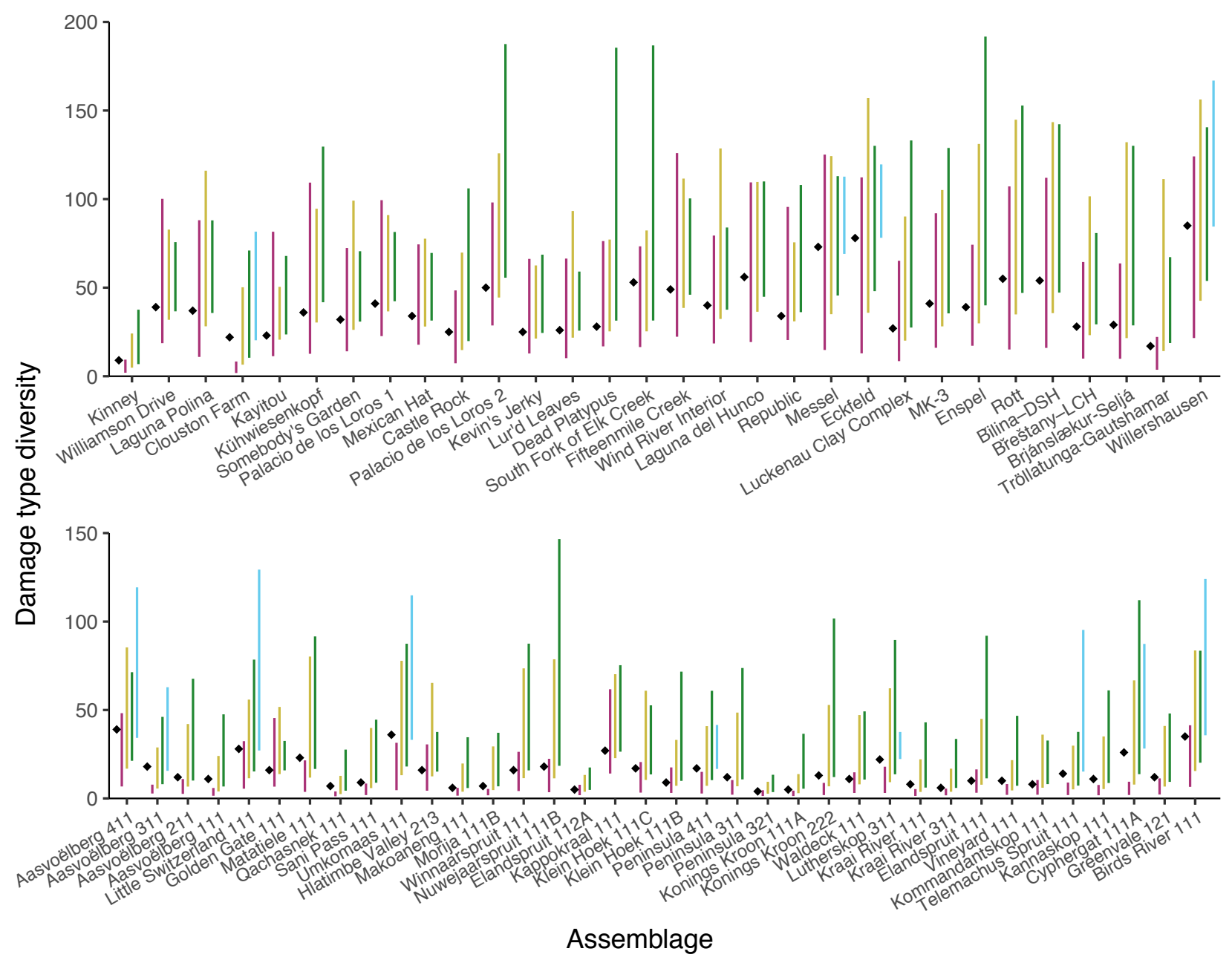

Figure S2: Precision and accuracy of the Chao1 estimator, examined by subsampling all assemblages listed in Tables 1 and 2. The black diamond denotes the raw damage type diversity observed at each assemblage and the lines denote the mean $95 \%$ confidence interval of the Chao1 estimator when used on a randomly sampled subset of leaves from the assemblage, as follows: magenta, 100 leaves; yellow, 500 leaves; green, 1,000 leaves; blue, 5,000 leaves. Not all assemblages contain sufficient material to subsample to 5,000 leaves. At low levels of sampling, the Chao1 estimator clearly underestimates damage type diversity. At higher levels of sampling, the Chao1 estimator becomes more accurate but far less precise. 

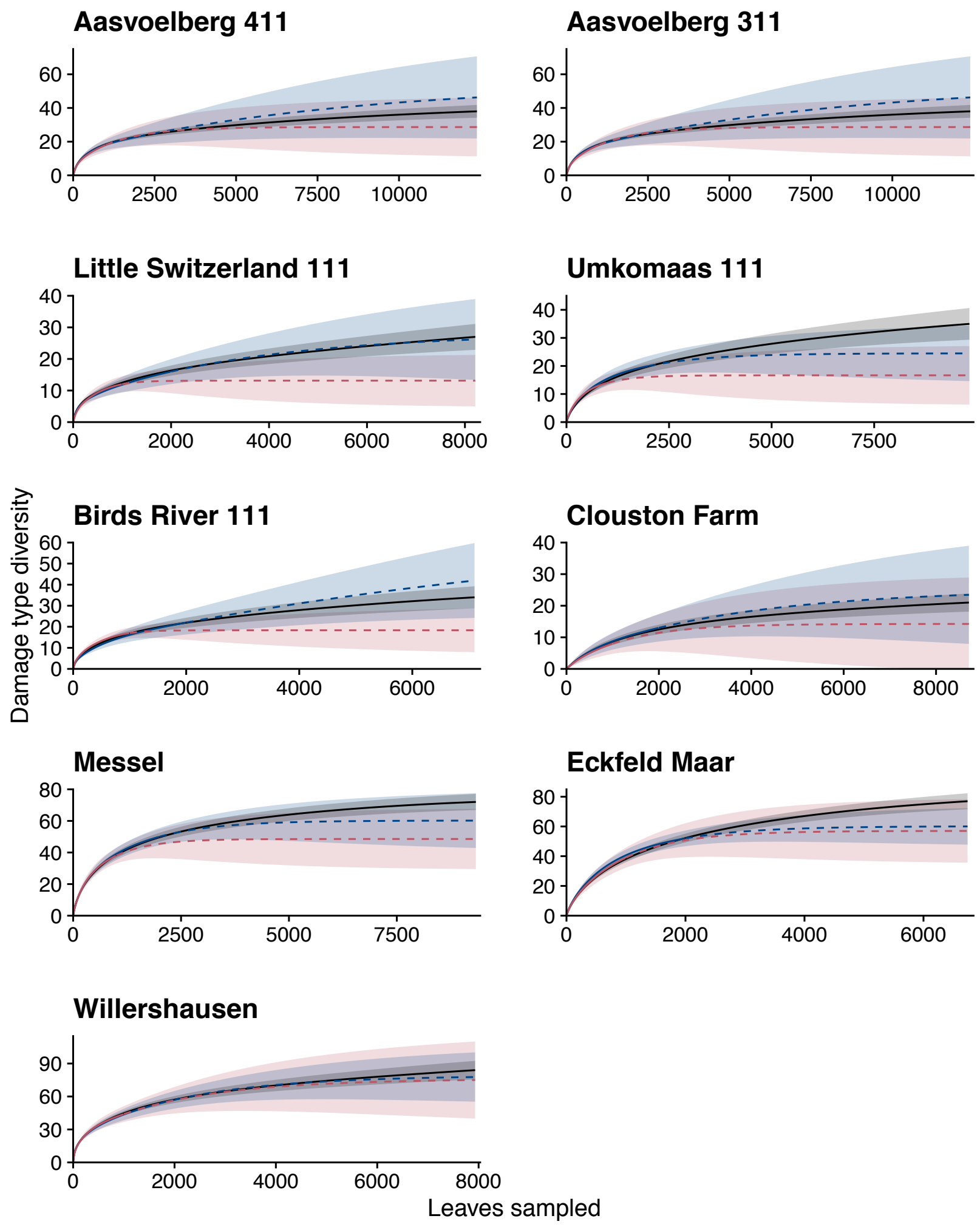

Figure S3: Precision and accuracy of estimates of damage type diversity generated with the method of Chao et al. (2014). Interpolated rarefaction curves are in solid lines and extrapolated curves are in dashed lines. The black lines represent the interpolated rarefaction curve for the raw dataset, the blue lines represent the raw dataset subsampled down to 2,000 leaves and then extrapolated to the number of leaves present in the raw dataset, and the red lines represent the raw dataset subsampled down to 1,000 leaves and then extrapolated to the number of leaves present in the raw dataset. 


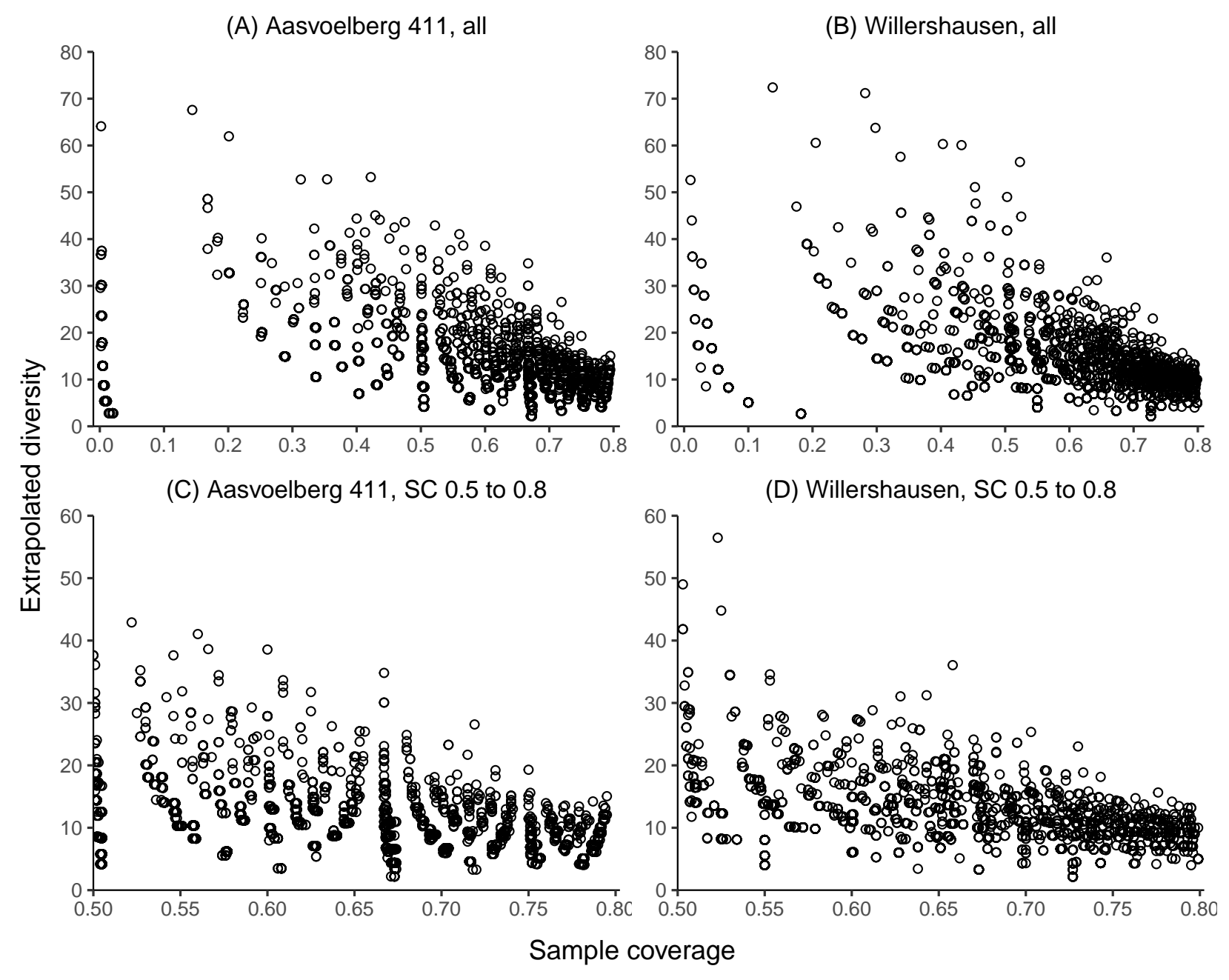

Figure S4: The variability of estimates of damage type diversity at a sample coverage of 0.8 when extrapolated from 1,000 subsampled leaves that yield a sample coverage below 0.8 . 
bioRxiv preprint doi: https://doi.org/10.1101/2021.07.16.452692; this version posted October 25, 2021. The copyright holder for this preprint (which was not certified by peer review) is the author/funder, who has granted bioRxiv a license to display the preprint in perpetuity. It is made available under aCC-BY 4.0 International license.
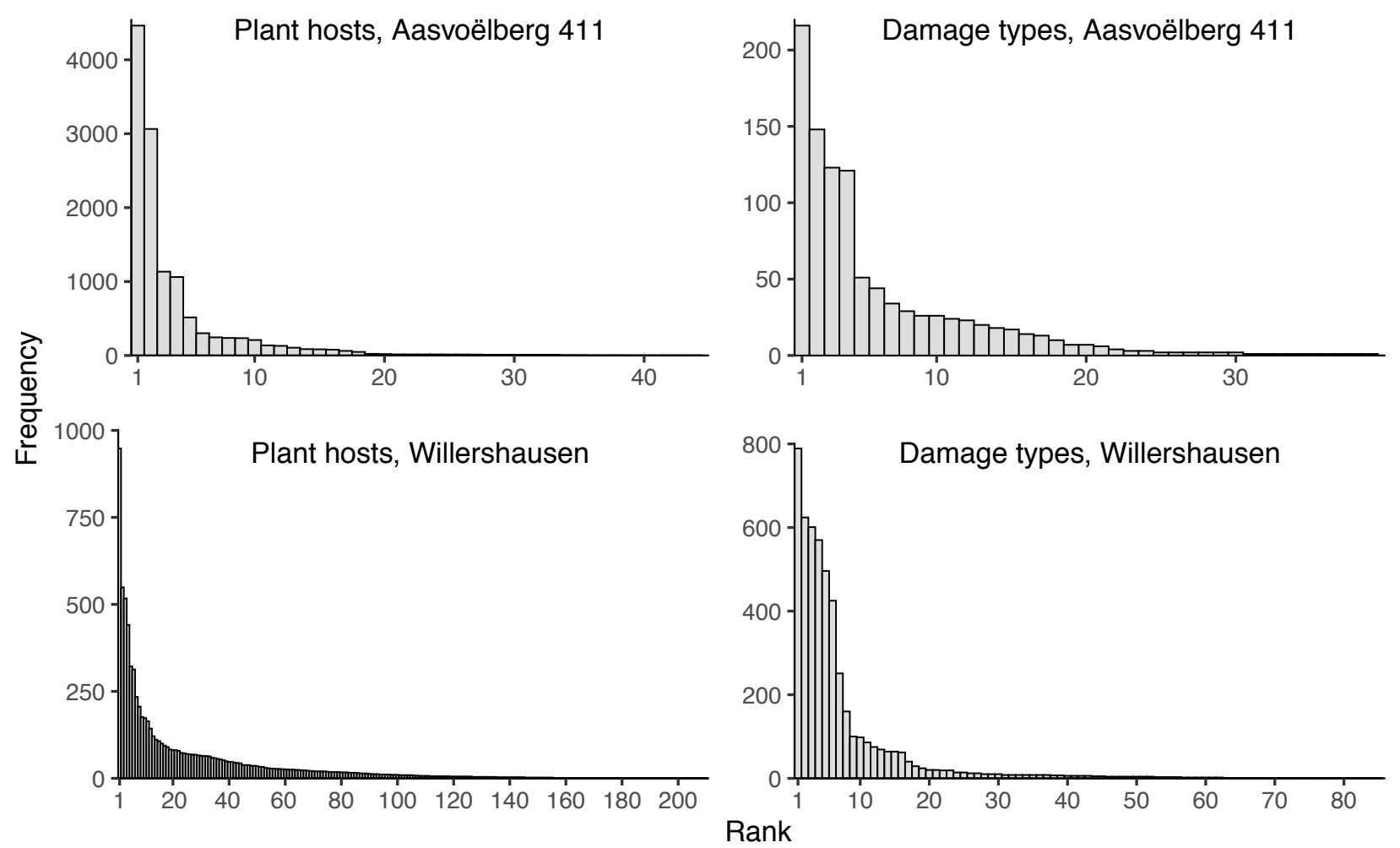

Figure S5: Dominance-diversity distributions for plant hosts and damage types at the pre-angiosperm assemblage with the largest number of leaves examined, Aasvoëlberg 411 (Labandeira et al., 2018), and the angiosperm assemblage with the largest number of leaves examined, Willershausen (Adroit et al., 2018).

(A) Damage types

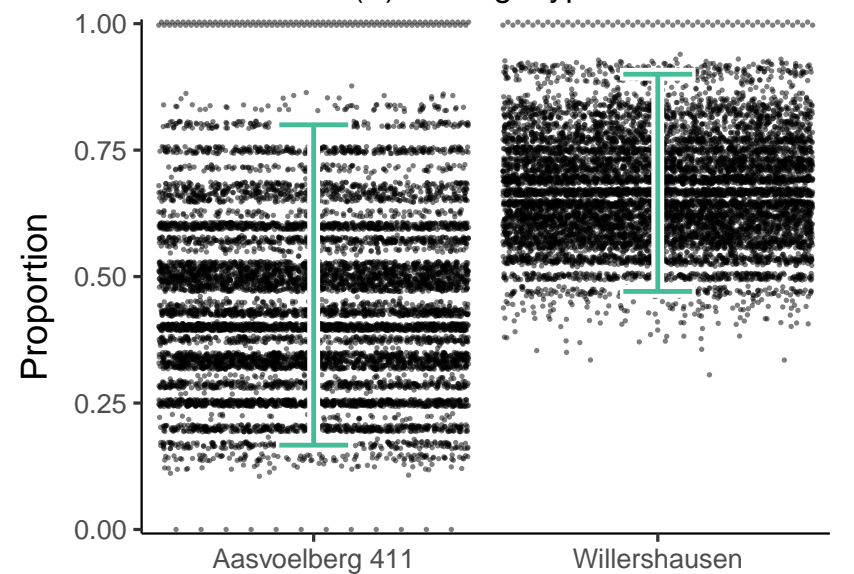

(B) Plant hosts

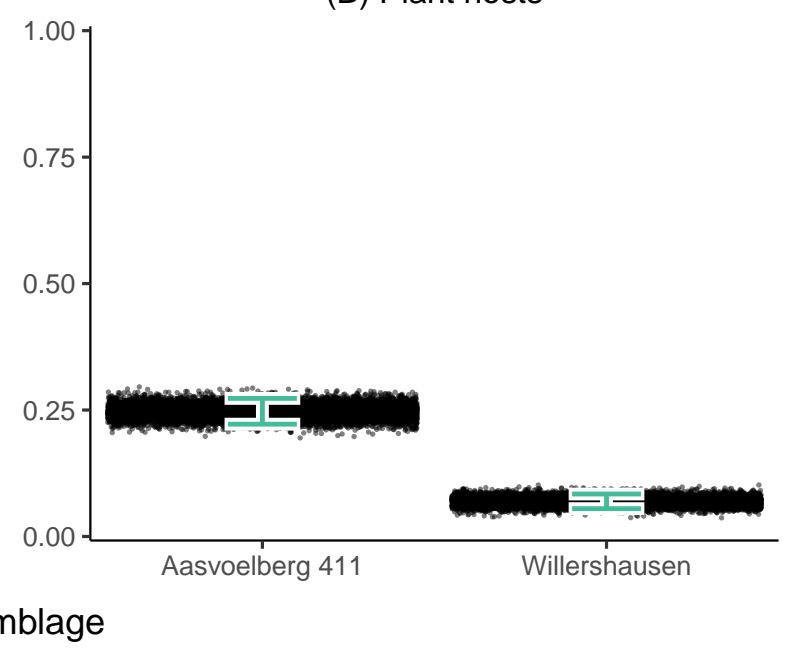

Figure S6: Measures of community structure at Aasvoëlberg 411 and Willershausen, the two assemblages featured in Figure S5, calculated by subsampling each assemblage to 1,000 leaves. Panel (a) shows the proportion of damage types on the second-most-abundant plant host that also occur on the most abundant plant host. Panel (b) shows the number of leaves belonging to the second-most-abundant plant host divided by the number of leaves belonging to the most abundant plant host. The lines denote $95 \%$ confidence intervals. 


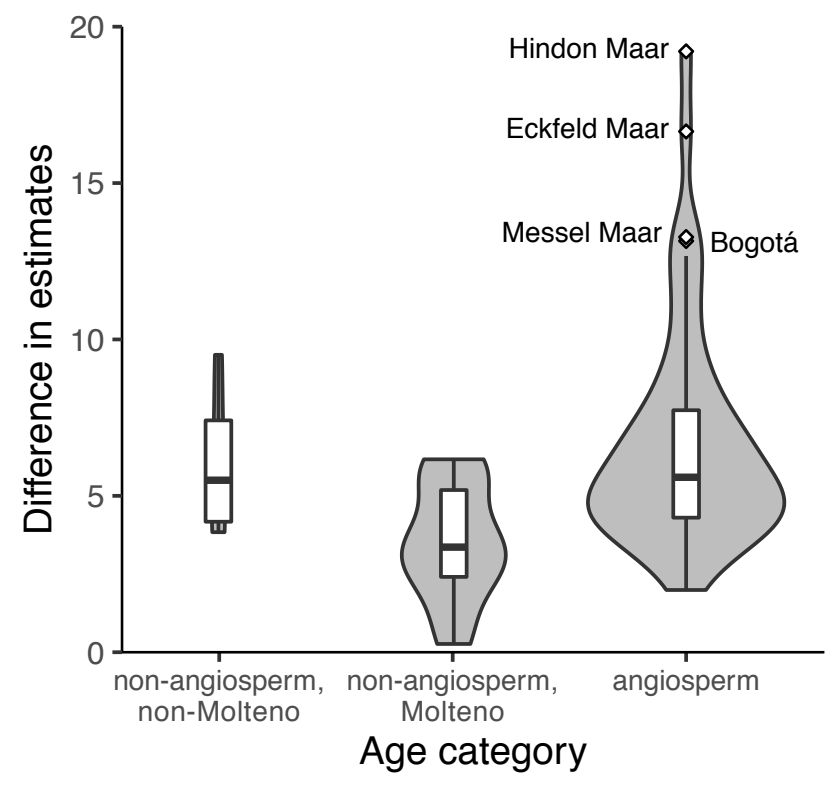

Figure S7: The difference in estimated damage type diversity when the sample coverage used in rarefaction increases from 0.8 to 0.9. The width of each violin represents the number of assemblages it contains. Boxplots are overlain atop each violin.

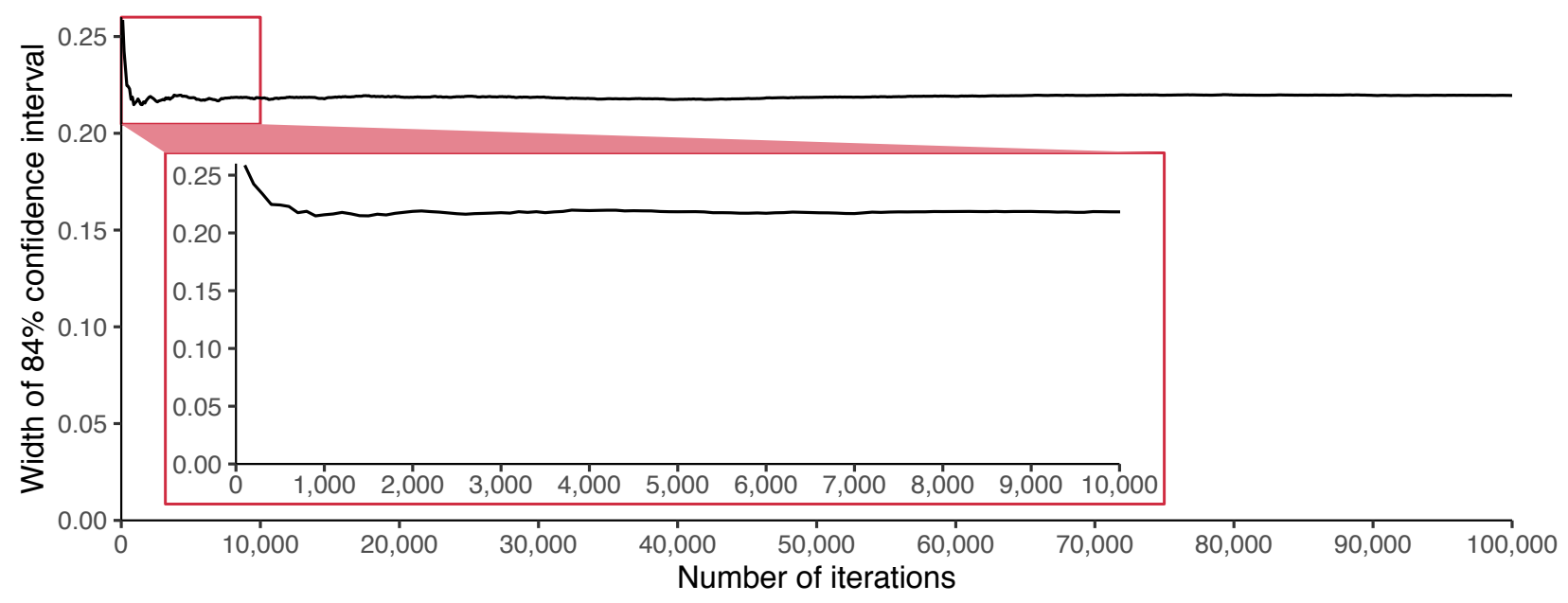

Figure S8: Changes in the width of the $84 \%$ confidence interval as the resampling procedure is further iterated. 